\title{
EL PROBLEMA DE LA FUNDAMENTACIÓN ÚLTIMA FILOSÓFICA A LA LUZ DE UNA PRAGMÁTICA TRASCENDENTAL DEL
} LENGUAJE

(Ensayo de una metacrítica del "racionalismo crítico")

\section{El problema: ¿racionalismo crítico contra fundamentación última?}

La tesis de la imposibilidad de una fundamentación última filosófica fue establecida en tiempo muy reciente por los sostenedores del llamado "racionalismo crítico", en nexo con la Lógica de la investigación de Popper, esperialmente por W. W. Bartley y H. Albert, y hecha valer contra el racionalismo clásico de la época moderna -y en ese contexto también contra la crítica del conocimiento, fundada por Kant con método filosófico-trascendental. ${ }^{1}$ El "racionalismo crítico" vincula con este distanciamiento de un racionalismo crítico, que no ha reflexionado aún críticamente sobre la imposibilidad de la autofundamentación, también la exigencia de poder sustituir en forma satisfactoria el programa filosófico de la fundamentación última con el programa de alternativa de una crítica racional ilimitada. Después de la proclamación de un "racionalismo pancrítico" por Bartley en su libro The Retreat to Committment, ${ }^{2}$ quien ha explicado especialmente este programa de alternativa es $\mathrm{H}$. Albert en su Traktat über kritische Vernunft. En ese contexto llevó él la crítica a la exigencia de una fundamentación filosófica última mediante la deducción del "trilema de Münchhausen", 3 llamado así por él, a una forma fácil de grabar en la memoria y pensada con claridad como lógicamente compulsiva.

De acuerdo con Hans Albert, todo intento de satisfacer la exigencia de fundamentación última filosófica en el sentido del postulado leibniziano de la "razón suficiente" (principium rationis sufficientis), conduce "a una situación con tres alternativas, todas las cuales aparecen inaceptables, es decir: a un trilema..." $\mathrm{El}$ intento, en efecto, constriñe según Albert a la elección entre:

“1. Un regreso al infinito, que aparece dado por la necesidad de retroce-

1 Asi Hans Albert, Traktak über kritische Vernunft, Tübingen, 1968, $2^{\text {a }}$ ed. 1969 , p. 15.

2 W. W. Bartley, The Retreat to Committment, Nueva York, 1962. (En alemán: Flucht ins Engagement, München, 1964.)

3 H. Albert, op. cit., p. 13 . 
der cada vez más lejos en la búsqueda de fundamentos, pero que en la práctica no puede llevarse a cabo $y$, por tanto, no proporciona ninguna base segura;

2. Un círculo lógico en la deducción, el cual surge de que en el procedimiento de fundamentación recurre uno a asertos que ya antes se habían presentado como faltos de fundamentación, y el cual, por ser lógicamente incorrecto, tampoco conduce a ninguna base segura, y finalmente

3. Una interrupción del procedimiento en un punto determinado, la cual por cierto aparece en principio realizable, pero involucraría una suspensión arbitraria del principio de fundamentación suficiente."

Ahora bien, Albert sabe que la tradición filosófica desde Aristóteles, pero especialmente el racionalismo iniciado por Descartes y su contrario, el empirismo, no pretendían suspender el procedimiento lógico de fundamentación en un punto cualquiera, con base en una suspensión arbitraria del principio de fundamentación, sino sólo al alcanzar unas premisas que, con base en evidencia conocitiva, fueran ciertas, evidentes o comprensibles. ${ }^{5}$ Albert argumenta, sin embargo, que puede "fundamentalmente dudarse" de cualquier premisa así, de manera que toda fundamentación mediante "evidencia" conocitiva desemboca al final, a pesar de todo, en una interrupción arbitraria del procedimiento de fundamentación en el sentido de la tercera alternativa del trilema.

Al respecto he aquí algunas comprobaciones textuales: el recurso a la "evidencia" en el procedimiento de fundamentación es, según Albert; "del todo análogo a la suspensión del principio de causalidad mediante la introducción de una causa sui". "Una afirmación, cuya verdad sea cierta y no necesite, por ello, ser fundada" es, según Albert, "un dogma"; fundamentación en el sentido de la tercera posibilidad es, por ello, "fundamentación mediante recurso a un $\operatorname{dog} m a$ ". Aun el "recurso a instancias extralingüisticas" no cambia nada, puesto que "también en relación con ellas queda siempre la posibilidad de preguntar por una fundamentación". "Toda tesis de autofundamentación para instancias últimas de esta clase, asi como tesis equivalentes para determinados asertos, tienen que considerarse como una máscara para la resolución de poner fuera de vigor el principio en ese caso." ?

Albert llega así no sólo al rechazo de la reducción cartesiana de la validez de la verdad a evidencia conocitiva, o a certeza, sino, por encima de esto, a la tesis de que el tender a la certeza es enteramente inútil, más aún, incompatible con la búsqueda de la verdad: "Todas las seguridades en el conocimiento son autofabricadas y por ello sin valor para la captatcion de la realidad. Esto es: Nosotros podemos procurarnos certeza constantemente,

4 Ibid.

5 Cfr. id. p. 14, así como pp. 15-28.

Id. p. 14 .

Id. Pp. $14 \mathrm{~s}$. 
al inmunizar contra toda crítica posible, mediante dogmatización, cualesquiera elementos de nuestras convicciones y asegurarlos, con ello, contra el riesgo del fracaso." \& Albert ve confirmada esta apreciación por $\mathrm{H}$. Dingler, quien no encuentra ya la última "seguridad" de la fundamentación filosófica del conocimiento en una evidencia dada, sino en la "voluntad" de certeza y, mediante el llamado principio de "exhaustión", inmuniza las construcciones teóricas del hombre contra el posible fracaso ante la realidad. Aquí -dice Albert"la voluntad de certeza" obtuvo la victoria sobre la "voluntad de conocimiento" " y así llevó ad absurdum el principio de fundamentación última del racionalismo clásico: "La evolución de la doctrina clásica ha... puesto en claro que la tendencia a la certeza y la búsqueda de la verdad en últìmo término se excluyen, si no quiere uno limitarse a verdades sin sentido [sin duda se hace referencia a los juicios analíticos]." 10

En vista de ese planteamiento de la cuestión, Albert recomienda, con Karl Popper, renunciar por completo al principio de razón o justificación suficiente y tomar una decisión - del todo opuesta a la de Dingler- imposible de fundar en última instancia en forma racional: es decir, una decisión en favor de un método que fundamentalmente no sustraiga a la posible critica ningún conocimiento tenido por cierto, sino que de manera consciente tienda a proporcionar a la realidad ocasión "de hacerse valer decisivamente", en virtud de que nuestras construcciones teóricas pueden fracasar ante ella."11 Tal decisión en favor del principio del "falibilismo" popperiano tiene ciertamente, según Albert, que "sacrificar la tendencia a la certeza, subyacente a la doctrina clásica, y conformarse con la permanente incertidumbre acerca de si nuestras concepciones se siguen confirmando también en el futuro y pueden, por tanto, sostenerse."12

Albert señala expresamente que así como para Dingler la "voluntad de seguridad" envuelve una "decisión moral", así también para Popper la aceptación del método de la prueba crítica: "ella significa la adopción de una praxis metódica de amplias consecuencias para la vida social y de gran im. portancia no sólo para la formación, el establecimiento, la elaboración y el examen de teorías, sino también para su aplicación y con ello, además, para el papel del conocimiento en la vida social". Es más, "el modelo de racionalidad del criticismo es el esbozo de una forma de vida, de una praxis social, y por ende tiene una significación ética y, más allá de ésta, política." 18 Las consecuencias de esta reflexión para la ética las saca Albert en el párrafo 12 ("Criticismo y Etica") de su tratado: Con Popper también él considera im-

8 Id. p. go.

Id. p. 34 .

10 Id. p. 39

11 Ibid.

12 Ibid.

13 Id., pp. 40 s. 
posible una fundamentación última de las normas éticas, pero, en lugar de esto, propone someter los sistemas morales vigentes, así como las teorías científicas establecidas, con respecto a su verificación de la realidad, a un constante examen crítico, de ser posible a la luz de alternativas. ${ }^{14}$

En lo que sigue yo deseo someter la posición del "racionalismo crítico", acabada de esbozar, a un examen metacrítico - en lo cual, por el momento, no se halla otra cosa que una autoaplicación del "racionalismo crítico". De ahí se aclara ya que mi meta no puede ser la puesta en duda del principio del "examen crítico". (¿Quién quisiera ya hoy día poner en duda en ese sentido el "racionalismo crítico"?) Sin embargo, sí deseo preguntar por las condiciones de posibilidad de una critica intersubjetivamente válida, es decir, del "examen crítico" de conocimientos cientificos así como de la crítica de normas morales. Este planteamiento, orientado hacia Kant, debe servir en especial para examinar el nexo interno afirmado por Albert entre la tesis de la imposibilidad de la fundamentación última y el programa positivo del "criticismo racional". Más exactamente: debe investigarse si $-y$ si sí, en qué sentido- el principio de fundamentación o justificación puede ser sustituido por el principio de la critica, o si - y si sí, en qué sentido- el principio de fundamentación o justificación más bien no es presupuesto por el principio de la crítica válida intersubjetivamente.

2. Reconstrucción critica del "trilema de Müchhausen": interpretación sintáctico-semántica contra la trascendental-pragmdtica de la idea de fundamentación suficiente

¿En qué consiste en la tradición el problema de la fundamentación última filosófica? - Desde la Antigüedad el problema de la fundamentación última filosófica se planteó en estrecha conexión con el conocimiento de la imposibilidad de una fundamentación lógico-matemática (apodíctico-deductiva) de los principios últimos (o primeros) - los llamados "axiomas"- del pensamiento lógico-matemático $y$, por ello, de las ciencias demostrativas. ${ }^{15}$ Dicho con nitidez: precisamente la circunstancia de que los argumentos lógico-ma-

14 Cfr., especialmente op. cit., pp. 77 ss. - Cfr., al respecto, abajo la nota 69 .

15 Como ilustración del clásico problema de la fundamentación última puede servir la del principio de la contradicción que debe ser evitada, en Aristóteles. Después de explicar, en el tercer libro de la Metafisica, primeramente la esencia de los "axiomas", llamados así por los matemáticos, e introducir luego el principio de contradicción como ejemplo de un axioma, prosigue: "Algunas gentes son, pues, de la opinión de que también éste tiene que ser demostrado - pero sólo porque les falta instrucción filosófica. Pues significa una falta de instrucción filosófica, cuando no se sabe para qué se debe buscar una demostración y para qué no. En efecto, es imposible que se dé absolutamente para todo una demostración: pues entonces serfa indispensable un progreso al infinito, de modo que por este camino no se llegarfa en absoluto a ninguna demostración... Sin embargo, por lo menos se puede demostrar mediante una refutación, que lo afirmado por nuestros adversarios es imposible, si es que se tiene ante sí un adversario que simplemente discuta. Ahora bien, si no lo 
temáticos no pueden por sí mismos fundar la verdad de sus premisas - y la validez de sus reglas deductivas-, sino que únicamente aseguran "la transferencia" del valor positivo de verdad - de la verdad - del conjunto de premisas a la conclusión y con ello también la retransferencia del valor negativo de verdad - de la falsedad - de la conclusión al conjunto de las premisas, ${ }^{16}$ ha planteado desde Aristóteles el problema de una fundamentación última filosófica. A esto responde que desde Descartes la concepción Aristotélica de los axiomas como principios inmediatamente evidentes, que ni son aptos para una demostración ni la necesitan, ${ }^{17}$ se interpreta y radicaliza en el sentido de que la fundamentación por recurso a la evidencia debe considerarse y postularse como fundamentación última filosófica. ${ }^{18}$ Con lo cual está ya señalado que el problema filosófico de la fundamentación última, tal como se planteó en la tradición, no puede concebirse como un problema puramente lógicaformal.

También Albert parece al principio tomar en cuenta esa situación, pues de modo expreso no hace valer el "principio de razón suficiente", formulado la primera vez por Leibniz, como "principio fundamental del pensamiento" o como "axioma de la lógica", según el modelo de viejos libros de lógica, sino que lo concibe como "postulado universal de la metodologia clásica del pensamiento racional", es decir: como un "principio metódico", en el cual se presupone que la "conocibilidad de la realidad y la comprobabilidad de la verdad... están acopladas una con otra".10 (De hecho, el postulado de fundamentación última del racionalismo clásico de la época moderna corresponde, a mi juicio, a una subordinación de la lógica - y de la teoria ontológica de correspondencia de la verdad- bajo la aspiración a la evidencia de una teorfa del conocimiento, ascendida al rango de prima philosophia. Esta subordinación de la lógica y de la ontología bajo el principio de evidencia de la teoria del conocimiento encontró su acuñación más radical en la fenomenologia de la conciencia de Brentano y Husserl.)

hace, sería ridiculo buscar argumentos frente a un hombre que no argumenta, por cuanto de hecho no lo hace. Un adversario semejante se parece, al conducirse así, casi a una planta. Yo distingo la refutación respecto de una demostración directa: cuando se quiere demostrar algo directamente, se expone uno a la apariencia de la captación de una fuente; si, en cambio, se hace que el adversario sea el conductor de la discusión, entonces se produce una refutación y no una demostración." (Metafisica, 4, 1006 a 6-18.)

16 Asf Albert, op. cit., p. 12.

17 Cfr. Aristóteles, Anal. post. I, 2, 71 b 20 ss.

18 Más exactamente debe decirse que Descartes coloca todavía la evidencia en sentido de la "clara et distincta perceptio" por delante de la verdad en sentido de la correspondencia ontológica entre pensamiento y estados de cosas, y en ese aspecto eleva a "primer principio" de su filosofía la autoconciencia cierta de su ser. Entre los axiomas fundados sobre las ideas claras y distintas, Descartes menciona por primera vez también la proposición: "Todo lo que es tiene una causa o un fundamento." (Cfr., por ejemplo, Principia I, 11.52 y Oeuvres, ed. Adam/Tannery, $7,112.135$ f. 164.)

10 Albert, op. cit., pp. 9 ss. 
En la introducción del "trilema de Münchhausen" Albert parte, sin embargo, de la lógica moderna —apoyándose en Popper y Carnap-, ${ }^{20}$ y causa la impresión de poder reducir la aporética del postulado racionalista de fundamentación última de la época moderna a un trilema deducible lógicoformalmente: a saber, al trilema, deducible en realidad de la exigencia de fundamentación última puramente deductiva, de: 1) un regreso al infinito, 2) un círculo lógico y 3) una interrupción infundada del procedimiento de fundamentación. ${ }^{11}$

Cualquiera que haya sido aquí la intención de Albert, una reconstrucción crítica de su argumento, dirigido contra el racionalismo clásico, ha de esclarecer aquí, a mi juicio, lo siguiente: La posible argumentación contra el postulado de evidencia del racionalismo clásico no tiene, de inmediato, absolutamente nada que ver con el tercer cuerno del trilema deducible de manera lógico-formal; más bien, el trilema de fundamentación lógica deducido por Albert únicamente puede ser entendido como explicación completa de aquella problemática de los "axiomas", ya señalada en Aristóteles, la cual desde un comienzo planteó antes que nadie el problema de una fundamentación última filosófica. Si reduce uno, con $\mathrm{D}$. Hilbert, el problema de la verdad de los principios fundamentales de la lógica y la matemática al problema de exención de contradicción de "sistemas axiomáticos", surge una aporética metalógica o metamatemática, correspondiente al trilema de Münchhausen, de la fundamentación última deductiva, como han mostrado entre otros Gödel y Church. ${ }^{22}$ Ya aquí se hace claro lo siguiente: a diferencia de la problemática lógico-matemática (y también metalógica y metamatemática) de la fundamentación última, el principio moderno de razón suficiente, en cuanto exige el recurso a la evidencia - proporcionado tal vez por la lógica-, es de antemano un principio epistemológico -un principio que, hablando modernamente, envuelve la dimensión pragmática (de la evidenecia para un sujeto de conocimiento).

De aquí se sigue para nuestra discusión: sólo cuando pudiera demostrarse que el postulado de la evidencia es por completo absurdo, de modo que desembocara efectivamente en la sustitución de la búsqueda de la verdad por una decisión arbitraria, sólo entonces sería legítimo reducir la aporética de la fundamentación última al tercer miembro del "trilema de Münchhausen", lógicamente deducible. La demostración de la inanidad del postulado de la evidencia, así exigida, no puede, sin embargo, por principio llevarse a cabo sólo con medios lógico-formales. Pero, ¿cómo puede, absolutamente, llevarse a cabo la demostración? ¿No debería, paradójicamente, presuponer

20 Cfr. id., p. 11

21 Id., pp. 11 ss.

22 Cfr., además ahora Hans Lenk: "Philosophische Logikbegrudung und rationaler Kritizismus", en H. Lenk, Metalogik und Sprachanalyse, Freiburg, 1973, pp. 88-169. 
ella misma de antemano, que el recurso a la "evidencia" no desemboca en una decisión arbitraria, sino que es indispensable para la argumentación filosófica?

En este punto necesito explicar mi estrategia de argumentación, a fin de prevenir malentendidos: en lo que sigue yo no deseo en modo alguno defender aquella posición del racionalismo clásico que, en el sentido del primado cartesiano del conocimiento - qua teoría de la conciencia - reduce la búsqueda de la verdad a búsqueda de la evidencia. Por tanto, no deseo defender ninguna "filosofía del origen", ${ }^{23}$ empirista o racionalista, del conocimiento, en la cual se defienda "una solución simultánea del problema del origen y de la validez". ${ }^{24}$ Semejante estrategia me parece ya poco prometedora, porque la evidencia conocitiva en cuanto tal, aun cuando pudiera ser indispensable, está restringida a la conciencia de evidencia en cada caso, y la teoría del conocimiento tradicional, qua teoría de la conciencia, no puede mostrar con sus medios lógicos, cómo la evidencia conocitiva, es decir, evidencia de juicios en cuanto enlaces de representación para una conciencia cualquiera, puede ser convertida en validez intersubjetiva de asertos formulados lingüisticamente. Pero dicha validez con base en una discusión crítica me parece ser un objeto metódico, perseguido con razón por Popper y sus discípulos, de la búsqueda cientifico-filosófica de la verdad.25 En que la "evidencia" de convicciones no le basta a una conciencia cualquiera para garantizar la verdad de asertos -en eso puedo yo concordar expresamente con Popper y Albert. Por sobre esto, de la circunstancia de que sola y únicamente el discurso critico de los científicos puede decidir sobre validez intersubjetiva de los resultados de la ciencia, yo voy a sacar ciertamente consecuencias teóricas de verdad, que la escuela popperiana no saca. En efecto, se desembocaría, a mi juicio, en un desconocimiento de la situación dél problema, si -como era usual en el empirismo lógico- la problemática, lingüisticamente proporcionada, de la validez intersubjetiva de asertos fuera declarada sin más como la de una lógica de la ciencia - sintáctico-semántica-, que pudiera remitir a la psicologia los problemas de la teoria del conocimiento tradicional.

Esta parece ser también la opinión de Albert, pues en la explicación del

28 Bajo este título T. W. Adorno se distancia del mismo tipo de teorfa del conocimiento moderna, que también rechaza $H$. Albert.

24 Cfr. H. Albert, op. cit., p. 29.

25 Con razón K. Popper, por ejemplo, acentúa contra la fundamentación teórico-evidencial de la matemática en el llamado "intuicionismo", la necesidad absoluta de la argumentación lingüística, que es la única que en última instancia puede dar origen a una decisión sobre la validez de las proposiciones matemáticas: "Tan pronto como la posibilidad de admitir una construcción matemática, propuesta intuicionistamente, es puesta en duda -y naturalmente puede serlo_, el lenguaje se muestra como algo más que un simple medio de comunicación, que en principio fuera indispensable; más bien se muestra como un medium indispensable de la discusión." ("Epistemology without a knowing subject", en Proceedings of the Third International Congr. for Logic, Methodology and Philos. of Science, Rootselaar-Staal (eds.), Amsterdam, 1968, p. 360 ). 
carácter de la metodología criticista tampoco admite él la reducción de la teorfa de la ciencia a una "aplicación -o tal vez a una parte- de la lógica formal, incluyendo partes importantes de la matemática y, en el mejor de los casos, aun añadiendo también quizá algunas partes de la semántica de lenguajes no-naturales" ${ }^{26}$ y exige - "en el sentido de la diferencia hoy usual entre sintaxis, semántica y pragmática" - la consideración de la "importancia gnoseológica de los nexos pragmáticos", ${ }^{27}$ es decir, de los estados de cosas lingüísticos y extralingǘsticos, que constituyen el contexto de los asertos problemáticos. Aquí pertenecen, según Albert, los "estados de cosas, a los que se refieren a los asertos correspondientes" y, "por sobre esto, también aquellos que constituyen el nexo de las actividades conocitivas humanas, es decir, empero, no sólo la aislada actividad de pensamiento y observación de los individuos singulares, sino también la discusión crítica en cuanto muestra de la interacción social, así como las instituciones, que la apoyan o debilitan, fomentan o reprimen". ${ }^{28}$ Con razón Albert saca de aquí la consecuencia de que su "crítica a la teoría del conocimiento clásico" ${ }^{29}$ y la necesidad, derivada de ahí, de una "elección entre el principio de fundamentación suficiente y el pincipio de examen crítico" caen en el "dominio de la pragmática". ${ }^{80}$

Yo deseo no sólo afirmar esta apreciación del estado del problema, sino tomarla en serio, en cuanto que no concibo con Carnap y Hempel las condiciones pragmáticas de posibilidad del conocimiento científico como condiciones contextuales empírico-psicológicas o emṕrico-sociológicas sin importancia para la problemática de la validez del conocimiento, sino, al menos parcialmente en el sentido de Kant, como condiciones de posibilidad del conocer intersubjetivamente válido y de la crítica (cientifica y filosófica) del conocimiento. Esta apreciación ha de estar justificada por lo menos en cuanto que la polémica, que cae en el "dominio de la pragmática", "entre el principio de fundamentación suficiente y el principio de examen crítico" - sea que desemboque o no en una decisión entre alternativas- se ocupa en todo caso de las condiciones de validez del conocimiento científico. Así pues, yo deseo postular como complemento filosófico de la sintaxis y semántica lógicas de lenguajes científicos ideales, una pragmática trascendental del lenguaje, que ha de ocuparse de la reflexión sobre las condiciones de posibilidad del conocimiento lingǘsticamente formulado $\mathrm{y}$, en cuanto tal, intersubjetivamente válido. En este sitio voy a tratar de resumir con toda brevedad lo más notable de la reconstrucción y complementación semiótico-trascendentales o

26 Albert, op. cit., p. 39 .

27 Id., p. 40.

28 Id., p. 39 .

29 Ibid.

so Id., p. 4 . 
pragmático-trascendentales de los fundamentos de la lógica moderna del lenguaje y de la ciencia, que he desarrollado en otra parte. ${ }^{31}$

La posibilidad y necesidad de un planteamiento pragmático-trascendental y de un método filosófico de investigación se puede, a mi juicio, demostrar en forma radical mediante reflexión sobre las condiciones de posibilidad y validez intersubjetiva de la sintaxis y semántica lógica mismas. En efecto, como ya reconocio $\mathrm{Ch}$. S. Peirce, es una implicación lógica de la bien entendida triplicidad de la relación de los signos, y a la vez del conocimiento y de la argumentación proporcionados por ellos, que sus funciones interno-lingüísticas (sintácticas) y relativas a la realidad (semántico-referenciales) presuponen una interpretación (pragmática) de ellos mediante una comunidad de interpretación..$^{32}$ Tal supuesto vale desde luego también para las disciplinas semióticas correspondientes; es decir: la sintaxis y semántica lógicas en cuanto disciplinas abstractivas parciales de la semiótica, en el sentido de una aclaración "indirecta" - es decir, proporcionada por sobre la construcción de sistemas de reglas ideales- de la argumentación científica o teórico-científica, ${ }^{33}$ están sujetas por principio a complemento e integración mediante una pragmática de la argumentación. Pero esto indica ya que la pragmática ha de ser una disciplina filosófica, que trate de las condiciones subjetivo-intersubjetivas del entenderse con sentido y de la formación de consenso en la comunidad -idealmente ilimitada - de los científicos. Esencialmente en ese sentido - a saber, como transformación semiótica de la "crítica de la razón pura" en el sentido de una lógica de la investigación, "normativa" y semiótica- ya fue concebida por Peirce según la cosa. ${ }^{34}$

Pues bien, Morris y Carnap adoptaron, por una parte, la fundamentación peirciana de la semiótica en el sentido de la tridimensionalidad de la función de los signos ("semiosis") y de la ciencia de éstos ("semiótica"); mas, por otra parte, explicaron su dimensión pragmática -obviamente en virtud de que la reflexión sobre las condiciones subjetivas actuales de la interpretación de los signos ${ }^{35}$ no puede, supuestamente, ser expresada en forma libre de contradicción - como el objeto de una disciplina empírica (conductista), a

31 Cfr. K. O. Apel, Programmatische Bemerkungen zur Idee einer transzendentalen Sprachpragmatik (en Studia Philosophica in Honorem Sven Krohn, ed. Timo Airaksinen èt alii, Turku, 1973, pp. 11-36; también en Semantics and Communication, ed. C. H. Heidrich, Amsterdam-London-New York, 1974, pp. $79 s s$ ) y del mismo: Zur Idee einer transzendentalen Sprachpragmatik (en Aspekte und Probleme der Sprachphilosophie, hersg. v. J. Simon, Freiburg i. Br. 1974).

32 Cfr., mi introducción a Ch. S. Peirce, Schriften II, Frankfurt a. M. 1970.

ss Cfr. Y. Bar-Hillel, "Argumentation in Pragmatic Languages" (en Y. Bar-Hillel, Aspects of Language, Jerusalem, 1970), especialmente pp. $208 s$.

${ }_{34}$ C fr., mi articulo 'Von Kant zu Peirce: die semiotische transformation der transzendentalen Logik" (en K. O. Apel, Transformation der Philosophie, Frankfurt a. M. 1972, T. II, pp. $157 \mathrm{~s}$ ).

8s Cfr., por ejemplo, Ch. Morris: Grundlagen der Zeichentheorie, München, 1972, pp. $50 s$ y 57 ss. 
cuya disposición, en todo caso, se pueden poner explicaciones conceptuales semánticas en una "pragmática" a su vez constructiva, "pura y teórica". Sea cual fuere lo que se sostenga sobre la posibilidad de tal tratamiento de la pragmática del lenguaje, ${ }^{36}$ lo cierto es que no puede tematizar filosóficamente las "convenciones", que, según Carnap, sirven de base a la construcción de sistemas de reglas sintáctico-semánticos formalizables - y, en ese sentido, también a la construcción de explicaciones semánticas de conceptos empíricopragmáticos. Pues las convenciones de importancia normativa, que ante todo hacen posibles las explicaciones lingüístico-formales de conceptos en el sentido de una pragmática teórica, no pueden ya ser hechas objeto de una pragmática empírica o de una construcción pragmático-formal. $Y$ por supuesto, la pragmática teórica del lenguaje, explícitamente prevista por Carnap -en cierta forma semantizada ya siempre a priori-, no puede sustituir tampoco a las argumentaciones metodológicas, consideradas como necesarias por Popper y Albert. En el sentido de la transformación semiótica de la filosofía trascendental, que hoy se exige, y en orden a los supuestos de la construcción moderna del lenguaje, sobre los que no se reflexiona ya de manera racional, podría caracterizarse directamente la función teóricocientífica de la pragmática trascendental como la de una reflexión sobre las condiciones de posi- . bilidad y validez de las convenciones. (Un sucedáneo tácito de semejante reflexión se puede encontrar en la lógica analítico-lingǘstica de la ciencia, proveniente de Carnap, en forma de "introducciones" provisionales al lenguaje ordinario, las que en rigor - a causa de las proposiciones universales ahí empleadas, implícitamente autorreflexivas - están concebidas en un "paralenguaje", no legitimable oficialmente. Ahí se halla, a mi juicio, la herencia del lenguaje-"escalera" del Tractatus de Wittgenstein, que no puede uno sacudirse en la lógica constructiva del lenguaje y de la ciencia, mientras no se reconozca una pragmática trascendental del lenguaje como última metadisciplina ya no formalizable.)

En el marco de la presente investigación deseo ahora poner a prueba la concepción indicada, intentando explicar a su luz la cuestión, demostrada ya como necesaria, sobre las condiciones de posibilidad de una critica intersübjetivamente válida. En el actual contexto del problema esto significa: yo deseo intentar, mediante recurso a la evidencia, reconstruir en forma pragmático-trascendental la crítica de Albert al postulado clásico de la fundamentación suficiente y examinarla de manera crítica.

Aquí resulta, en primer lugar, que el llamado "trilema de Münchhausen" de la fundamentación suficiente sólo se puede deducir en forma lógica con relación a proposiciones o a sistemas proposicionales, axiomáticamente ordenados, en el sentido de la construcción sintáctico-semántica de los llamados

so Cfr., mi Introducción crítica a Ch. Morris, Zeichen, Sprache und Verhalten, Düsseldorf, 1973 . 
"lenguajes formalizados", lo cual, sin embargo, quiere decir: bajo abstracción previa de la dimensión pragmática del uso argumentativo del lenguaje. Dicho de otra manera: sólo cuando se prescinde por anticipado de la situación del sujeto conocente y argumentante, que pone a discusión sus dudas y sus certezas en afirmaciones (statements) explicadas de manera realizativa, se puede caracterizar sin más el recurso a la evidencia -proporcionado deductivamente- como interrupción del procedimiento de fundamentación y equipararlo al regreso al infinito y al círculo lógico como tercer cuerno del trilema. En efecto, sólo bajo el punto de vista sintáctico-semántico de la abstracción -el cual no puede sujetar mediante deixis objetiva ni subjetiva (personal) el lenguaje y a la vez el conocimiento al mundo vital_ es posible comprender el sentido del proceso de fundamentación como una deducción, que por principio no puede interrumpirse, de proposiciones (sobre estados de cosas) a partir de proposiciones. Desde el punto de vista pragmático-trascendental, por el contrario, el procedimiento deductivo de la reducción de proposiciones a proposiciones -y en ese aspecto toda "axiomática"- puede ser considerado de antemano sólo como medio -objetivable por cierto- en el contexto de la fundamentación argumentativa de asertos afirmados mediante evidencias conocitivas. (En ese sentido la "lógica apodíctica" fundada por Aristóteles es de hecho un "órganon". del discurso argumentativo - no menos, pero tampoco más. Es decir: la deducción lógica misma de proposiciones a partir de proposiciones no es ya la fundamentación de la validez del conocimiento. -tal absolutización del órganon lógico reduciría de hecho, trivialmente, el problema de la fundamentación al "trilema de Münchhausen"-, sino sólo un momento intermediario, caracterizado por evidencia a priori intersubjetiva en el proceso argumentativo de fundamentación.)

A esto responde la importante distinción que sigue, la cual fue pasada por alto, significativamente, no sólo por los empiristas lógicos, sino también por K. Popper —al menos en la Lógica de la investigación-: sólo cuando -en forma ilegítima, es decir, en el sentido de una "abstractive fallacy"se prescinde definitivamente de la función interpretativa pragmático-trascendental del sujeto de conocimiento y argumentación, y éste es reducido previamente a un objeto de psicología empírica, se puede hablar de que las proposiciones sólo pueden ser fundadas por proposiciones y de que las llamadas "proposiciones de observación" o "de base" de la ciencia son motivadas, exclusivamente en el sentido de una causación, por las "evidenecias experienciales", vividas por los sujetos de conocimiento. ${ }^{37}$ Para una forma de consi-

$37 \mathrm{~K}$. Popper escribe en la Logik der Forschung ( $3^{\text {a }}$ ed., Tübingen, p. 71): "Experiencias pueden motivar resoluciones, por tanto, también estipulaciones, pero no pueden fundar una proposición base, tan poco como no lo puede hacer un puñetazo sobre la mesa." En la edición inglesa Popper habla incluso alternativamente de una relación motivacional y otra causal (Cfr. Logic of Scientific Discovery, loc. cit., p. 105. Al respecto, critica. mente: P. Bernays, "Reflections on Karl Popper's Epistemology", en The Critical Approach 
deración pragmático-trascendental, por el contrario, situada en el punto de vista del sujeto que conoce y argumenta -es decir, cuya "conducta" en la formulación proposicional no trata de explicar desde fuera, sino entender desde dentro-, para esa forma de consideración la evidencia conocitiva es, por supuesto, un fundamento en orden a la formulación de "proposiciones de observación" o "de base" - aun cuando no sea ningún fundamento, desde el cual puedan ser deducidas en forma lógica esas proposiciones.

De ningún modo está implícito ahí necesariamente, a mi juicio, que las evidencias conocitivas - por ejemplo, percepciones o intuiciones ideales (categoriales) - tuvieran que o pudieran ser consideradas como base infalible y suficiente, independiente del lenguaje, es decir, prelingüisticamente intuitiva, del sentido y de la verdad de asertos científicos o sistemas de asertos ("teorias"). Esta concepción corresponde más bien a la filosofía epistemo

to Science and Philosophy, Essays in Honor of Karl Popper, London, 1964, p. 38) - A. Wellmer observa sobre ello con razón: "No se requiere el método del análisis del lenguaje, menospreciado por Popper, para demostrar como insostenible la idea de una relación motivacional entre la experiencia y su articulación lingüistica... El pasa por alto que no solo las proposiciones de experiencia, sino las experiencias mismas, trascienden su respectivo aquí y ahora." (Methodologie als Erkenntnistheorie. Zur Wissenschaftslehre Karl R. Poppers; Frankfurt a. M. 1967, p. $15^{6} s$.) - Popper, sin embargo, obviamente no conoce, igual que los empiristas lógicos, una alternativa conceptual para la disyunción entre nexos lógicos proposicionales y nexos de motivación empírico-psicológicos (externo-causales), o también entre universales lingülsticos y experiencias de evidencia prelingüisticas individuales. $\mathbf{Y}$ bajo este supuesto - nominalista-, Popper tiene razón cuando reprueba también las "proposiciones protocolarias", qua "protocolos de experiencia", de los neopositivistas todavia como psicologismo (Gfr. Logik der Forschung, loc. cit., pp. 61 ss). Naturalmente no queda entonces otra cosa que reducir la validez de las "proposiciones base" a la de "decisiones base". Suponiendo, sin embargo, que nuestras experiencias evidentes son siempre experiencias interpretadas lingüisticamente y trascienden en cuanto tales su respectivo aqui y ahora, entonces se puede pensar que, por un lado, su evidencia en cuanto dependiente de interpretación jamás es infalible; pero, por otro, muy bien puede y tiene que fungir como fundamentación interna del contenido significativo de nuestros juicios de experiencia, articulados lingüisticamente. No puede uno, por supuesto, remitirse a tal evidencia experiencial en la forma en que un psicólogo explica las convicciones de un hombre mediante vivencias evidenciales qua causas, pero sí puede uno en la argumentación - y aun en la argumentación crftica- remitirse a evidencias objetivas en la forma de un testimonio subjetivo. Popper tampoco conoce este concepto de evidencia - presupuesto en la fenomenologia trascendental sino que equipara - como el empirismo lógico, sólo que en el veredicto del psicologismo todavia más consecuentemente- "evidencia" en el sentido de la teoría del conocimiento, a vivencias o sentimientos evidenciales en el sentido de la psicologia empirica (cfr. op. cit., pp. $20 s$ y $64 s s$ ) - como si no perteneciera tampoco a las condiciones, si no suficientes, sí al menos necesarias, de una evidencia de conocimiento psicológicamente válida. Si se reduce el criterium de verdad (en el sentido de un indicador que nunca falla) de la evidencia objetiva (la cual sin duda tiene que poder ser testificada por un sujeto conocente) a un sentimiento de evidencia subjetivo, aún por tematizar psicológicamente, entonces se produce, claro está, la necesidad de sustituir el pensamiento de la posibilidad objetiva de fundar simplemente por el de revisabilidad o criticabilidad ilimitada (cfr. Popper loc. cit.). Pero, ¿qué sentido tiene todavía ahora la idea de la revisión o de la crítica? $\mathrm{La}$ indicación de que en la praxis puede evitarse un regressus ad infinitum mediante "resoluciones", apenas puede sin duda ser una respuesta satisfactoria a la pregunta por el sentido positivo de la critica. 
lógica "del origen" (empirista o intelectualista) de la época moderna, que - como ya se mencionó - no deseo yo defender. En virtud de los "actos proposicionales" (es decir, los actos identificadores de "referencia" y "predicación"), ${ }^{38}$ de los que la formación del juicio es dependiente, las evidencias conocitivas están desde el principio, a mi juicio, entretejidas con el uso del lenguaje y las actividades de los sujetos conocentes - en el sentido del entreteje de conocimiento, uso lingüístico y praxis vital en "juegos de lenguaje" o "formas de vida" cuasi institucionalizados, como las analizó el Wittgenstein posterior. Si no existiera este entreteje, un niño no podría aprender el lenguaje y con este, al mismo tiempo, formas de conducta que estén en armonía con la experiencia interpretada. Es decir, sin evidencias experienciales paradigmáticas no puede pensarse un juego de lenguaje funcional. Nosotros no podríamos darnos a entender, si no coincidiéramos ya siempre sobre evidencias experienciales, de las que cada uno ha de partir. De este entreteje de juego lingüístico pragmático-trascendental de las posibles evidencias conocitivas, se sigue, a mi juicio, que la fundamentación de la validez del conocimiento no puede ser equiparada ni con la deducción lógica de proposiciones a partir de proposiciones en sistemas axiomatizados, como lo hace la moderna lógica del lenguaje o de la ciencia, ni con el recurso a intuitiva evidencia de conciencia independiente del lenguaje, como hace suponer la moderna teoria del conocimiento de origen cartesiano. Más bien la fundamentación, en cuanto lo es de la validez del conocimiento, tiene que apoyarse siempre al mismo tiempo sobre las posibles evidencias de conciencia de los sujetos conocentes individuales capaces (como representantes autónomos del sujeto conocente trascendental en general) y sobre las reglas a priori intersubjetivas de un discurso de argumentación, en cuyo contexto las evidencias de conocimiento, como testimonios subjetivos de validez objetiva, tienen que alcanzar una validez intersubjetiva. Que esto es necesario y también posible, se garantiza por el "entreteje" a priori -pragmático-trascendental- de evidencias conocitivas, que pueden interpretarse en su contenido _- "como algo"-, y reglas del uso del lenguaje, descubierto por Wittgenstein y concretado y precisado especialmente en el entreteje, hecho explícito por Austin, Strawson y Searle, de actos judicativos, como actos de referencia y predicación, con actos de hablar: en virtud de esta concepción no tiene ningún sentido de posibilidad hablar de un "recurso a la evidencia conocitiva", sin presuponer un discurso lingüístico como contexto de interpretación y de coherencia lógica, ni tampoco tiene sentido alguno de posibilidad pensar siquiera un discurso de fundamentación pleno de contenido y argumentativo, sin suponer determinadas evidencias conocitivas, que cada uno de los participantes en el discurso introducen como criterios de verdad, decisivos para ella en la forma.

38 Cfr., a este respecto J. R. Searle: Speech Acts, Cambridge, 1969. (En alemán: Sprechakte, Frankfurt a. M., 1971, cap. 2.) 
ción argumentativa del consenso. - El entreteje de juego lingüístico, recién esbozado, de evidencias conocitivas constituye, a mi juicio, la explicación pragmático-trascendental de que todas las experiencias cientificas, como hoy se dice, estén "impregnadas de teoria" y de que las evidencias conocitivas que entran en las proposiciones base sean dependientes más o menos de las teorías por comprobar o falsificar -0 , también, de teorías de alternativa. ${ }^{39}$

Ahora bien, de acuerdo con Albert, se podría objetar: que el tratamiento usado hasta hoy del problema de la fundamentación suficiente por medio de evidencia conocitiva parte de una explicación inadecuada -esto es, empobrecedora - del concepto de "fundamentación" o "evidencia", presupuesto por él; que la fundamentación mediante evidencia en el sentido del racionalismo clásico - se podría decir así- es fundamentación última por medio de algo definitivamente seguro, es decir, indubitable; que la búsqueda metódica de la verdad es inconciliable con esto, porque ella no puede reconocer - de acuerdo con el principio del "falibilismo"- ninguna certeza definitiva, indubitable. Consideremos más en detalle este argumento y partamos para ese fin del dicho de Albert según el cual "propiamente se puede dudar en principio de todo".

3. ${ }_{3}$ Contradice el principio del falibilismo a la suposición de la evidencia indudable?

El principio del "falibilismo" - establecido la primera vez, en lo que yo sé, por Ch. S. Peirce,40 -designa de hecho, a mi juicio, un supuesto indispensable de la metodologia de las ciencias empiricas- el cual distingue las ciencias empiricas de la época moderna, según su idea, del concepto de "episteme" de la ciencia filosófica fundada sobre la visión de la esencia, según Platón, el idealismo alemán y aún E. Husserl. Pero, ¿no supone precisamente esta distinción -así como el conocimiento reivindicado por Albert de la distinción entre búsqueda de la evidencia y búsqueda de la verdad (o entre criticismo y racionalismo de fundamentación) - a su vez una visión evidente de la esencia en el sentido de un conocimiento filosófico?

39 Yo no puedo aquí entrar en las consecuencias teórico-cientıficas, que resultan de la idea del entreteje de juego lingüistico de las evidencias experienciales. Sin embargo, sea indicado lo siguiente: si las evidencias experienciales apenas pueden ser consideradas como base libre de interpretación de la validez intersubjetiva de conocimiento, menos puede ser entendido su entreteje de juego lingürstico como dependencia inequívoca de un uso de lenguaje teóricamente precisado. Esa consecuencia, tal como la saca en especial Feyerabend siguiendo a T. Kuhn, conduce a un relativismo de juego lingüístico o de teorias, que K. Popper sin duda con razón ha caracterizado como un "myth of the frameworks". No sólo existen "juegos lingǘsticos", sino que en todos ellos se encuentra el juego trascendental de lenguaje de la ilimitada comunidad de comunicación.

to Cfr., mi edición de Ch. S. Peirce, Schriften, I y II. Frankfurt a. M. 1967 y 1970, Indice de materias. 
Con todo, yo no deseo hacer valer esta pregunta retórica ya como un contraargumento definitivo contra el "racionalismo pancrítico" (Bartley), sino conceder, en primer término, que el principio del "falibilismo" —en un sentido todavia por explicar, naturalmente- debe aplicarse aun a los puntos de vista de las ciencias formales (lógica y matemática) y de la filosofía trascendental. Sin embargo, en cierta medida para compensar esta concesión, yo quisiera reivindicar, por otra parte -en un sentido igualmente todavía por explicar- aun para las ciencias empíricas, la indispensabilidad metodológica de la evidencia en sentido de una certeza indubitable. Yo quisiera dilucidar el sentido de estas tesis con base en una discusión del dicho albertiano, de que "propiamente se puede dudar en principio de todo".41 A la dificultad que se oculta en esta proposición -expresada frecuentemente por los filósofos en forma ligera-, hace alusión ya la circunstancia históricamente notable, de que el fundador del principio del "falibilismo", Ch. S. Peirce, al mismo tiempo polemizó contra Descartes con el argumento de que no se podría dudar de todo, a menos que la duda desembocara en una "paper doubt" vacia de contenido. ${ }^{42}$ Una duda razonable supone, según Peirce, precisamente en la ciencia empírica, que no se dude de todo, sino que se parta de convicciones que uno tiene por ciertas y acepta como criterio para lo que ha de dudarse y para las nuevas evidencias tenidas fundamentalmente como posibles.

Muy similares argumentos critico-significativos se encuentran en el Wittgenstein posterior.43 Así, en la colección de aforismos Sobre la certeza, el n ${ }^{115}$, dice: "Quien pretendiese dudar de todo, ni siquiera llegaria hasta la duda. El juego mismo del dudar presupone ya la certeza." En otras palabras: como juego lingüístico con sentido, el dudar - y por lo mismo también la crítica según Popper y Albert- no puede explicarse sin presuponer a la vez en principio certeza indubitable. $Y$ Wittgenstein generaliza y radicaliza esta concepción una vez más en el aforismo 114: “Quien no está cierto de ningún hecho, tampoco puede estar cierto del sentido de sus palabras." " Dicho de otra manera: todo juego lingǘstico que funcione - todo entendimiento sobre sentido- presupone que los compañeros de comunicación, quienes tienen que haber aprendido el lenguaje junto con una acreditada orientación hacia el mundo, consideren como ciertos numerosos hechos objetivos. (En un sentido preciso, las convicciones de las que no puede dudarse o que no pueden corregirse - ya sean principios o hechos contingentes - fungen como "muestras" o "paradigmas" del uso lingǘstico pleno de sentido.45 Asi, por ejemplo, la convicción de que la Tierra es una esfera que gira sobre sí misma

11 Albert, op. cit., p. 14 .

42 Ch. S. Peirce, Collected Papers, V. $\$ \$ 265$ y 376.

$43 \mathrm{La}$ indicación de los pasajes de Wittgenstein que siguen, la debo en parte a un trabajo de Dieter Mans.

4 L. Wittgensteìn: Uber Gewissheit, Frankfurt a. M. 1970, p. 39. 
y alrededor del Sol, es un "paradigma" de juego lingüístico para nuestros posibles interrogantes con sentido en la aeronáutica y en la meteorología; y la convicción de que se da un mundo exterior real "fuera" de la conciencia, es un paradigma de juego lingüístico para la cuestión crítica sobre si algo es real o quizá se apoye en la imaginación, ilusión, alucinación o semejantes.) De aquí parece seguirse que (también) la fundamentación en la vida cotidiana y en la ciencia tiene que reducirse a la evidencia presupuesta conforme al sentido en el juego lingüistico. El "recurso a la evidencia", por tanto, al menos en ese aspecto no puede equipararse con el "recurso a un dogma" o con el "recurso a una decisión arbitraria"; pues aun la crítica misma - como crítica con sentido en el marco de un juego lingüfsticotiene que estar fundada por lo menos virtualmente; pero esto significa: aun ella tiene que poder ser reducida en principio a la evidencia. Dicho de otra manera: la crítica no puede - como da la impresión en Bartley y Albert-, por decirlo así, ser última instancia autosatisfactoria de argumentación racional: ella tiene que presuponer, a su vez, un marco pragmático-trascendental - un juego lingüístico con sentido-, en el que posibles argumentos criticos y posibles fundamentaciones correspondan en principio unos a otras mediante recurso a evidencia "paradigmática". Esto parece constituir en cier. ta medida la estructura esencial de la institución del argumentar. Wittgenstein parece opinar cabalmente esto cuando escribe: "Toda prueba, todo corroborar e invalidar una suposición sucede ya dentro de un sistema. $Y$ este sistema, por cierto, no es un punto de arranque más o menos arbitrario o dudoso de todos nuestros argumentos, sino que pertenece a la esencia de lo que llamamos un argumento." 18

45 Cfr., por ejemplo L. Wittgenstein: Philosophische Untersuchungen, I, \$ 50: "No se puede afirmar de una cosa que es de $1 \mathrm{~m}$. de largo, ni tampoco que no es de $1 \mathrm{~m}$. de largo, y ése es el metro original de París. - Con ello, empero, no le hemos atribuido a él, naturalmente, ninguna propiedad singular, sino que sólo hemos caracterizado su peculiar papel en el juego del medir con la medida métrica. Imaginémonos que de manera semejante al metro original, también está conservada en Paris una muestra de los colores. Asf explicariamos nosotros: 'sepia' se llama el color del sepia original conservado allá bajo protección contra el aire... Esta muestra es un instrumento del lenguaje, con el que hacemos afirmaciones sobre los colores... Lo que, aparentemente, ha de darse, pertenece al lenguaje. En nuestro juego hay un paradigma; algo, con lo que es comparado." Además I, \& goo: "Al juego de lenguaje con las palabras 'El tiene dolor' pertenece -podría decirse - no sólo la imagen del comportamiento, sino también la imagen del dolor. $O$ : no sólo el paradigma del comportamiento, sino también el del dolor." Con clara referencia a las convicciones, ciertas a priori, se dice asl en las Bemerkungen zu den Grundlagen der Mathematik (Oxford 1956, pp. 3o s.): "¿De dónde la percepción: 'Blanco es más claro que negro' dice algo sobre la esencia de los dos colores? - ... ¿No es más bien asi: la imagen de un punto negro y de uno blanco... nos sirve al mismo tiempo de paradigma de aquello que nosotros entendemos por más claro y más obscuro, y como paradigma para 'blanco' y para 'negro'?... aquel enlace, un enlace de paradigmas y nombres se ha producido en nuestro lenguaje. $Y$ nuestra proposición es intemporal, porque expresa únicamente el enlace de las palabras 'blanco', 'negro' y 'más claro' con un paradigma."

$\$ 6$ L. Wittgenstein: Uber Gewissheit, Aphorismus 105, loc. cit. p. $3^{6 .}$ 
A través de esta argumentación crítico-significativa de procedencia peirciana y wittgensteiniana se muestran indudablemente como insostenibles numerosas tesis programáticas, imprudentes o exageradas del "racionalismo pancrítico" de procedencia bartleyiana y albertiana. Entre ellas están, por ejemplo, la equiparación indiferenciada de la fundamentación suficiente por medio del recurso a la evidencia con el recurso a un dogma o a una decisión arbitraria, así como la propuesta de poner "en lugar de la idea de fundamentación la idea de una prueba crítica". El lenguaje de los "racionalistas críticos" sugiere de hecho no pocas veces el malentendido de una crítica anárquica por la crítica misma, de una razón crítica sin normas de crítica.

Con todo, la discusión no puede concluirse aún en este punto; lo más notable del "racionalismo crítico" (me) parece no haber sido todavía comprendido realmente. Esto se desprende ya de que el sentido del principio del "falibilismo", que — como ya se dijo- también Peirce sostuvo, no está aún aclarado. Intentemos esto en un segundo impulso.

En su confrontación con Descartes, Peirce aclara según el sentido que en la ciencia ciertamente no tiene que poder dudarse de todo a la vez - por ejemplo, de la existencia de un mundo exterior real en conjunto-, ${ }^{47}$ pero sí virtualmente de todo, es decir, de cada cosa considerada como evidente- por ejemplo, bajo ciertas circunstancias, de la realidad de cada elemento fáctico considerado como perteneciente al mundo exterior real. Esta duda virtualmente universal -que en Peirce corresponde manifiestamente al principio del falibilismo- parece tenerla también ante los ojos Albert, cuando escribe: "Un criticismo consecuente, que no admite dogmas de ninguna clase, implica... de modo necesario un falibilismo respecto de cualquier instancia posible", y: "No se da ni una solución del problema, ni una instancia competente para la solución de determinados problemas, la cual necesariamente y de antemano tuviera que sustraerse a la crítica." 48

Sin embargo, ¿cómo puede este postulado del "falibilismo" ponerse en consonancia con $\mathrm{el}^{-}$punto de vista crítico-significativo de Peirce y Wittgenstein, según el cual toda duda y toda crítica en principio - a saber, como elemento constitutivo de un juego científico de argumentación pleno de sentido - tiene que poder fundarse suficientemente por medio de una evidencia que se supone indubitable?

Peirce mismo tuvo grandes dificultades para poner en consonancia su

47 Que no se puede dudar con sentido del mundo exterior real en su totalidad, puede mostrarse muy bellamente también desde el Wittgenstein posterior: Por ejemplo, no se puede, con Descartes, argumentar razonablemente que todo lo que vale como real, es al fin meramente mi sueño (o: existe simplemente en la conciencia); pues la expresión "meramente mi sueño" (o "simplemente en la conciencia") tiene sentido sólo en el marco de un juego de lenguaje, en el cual se presupone como paradigma, que no todo lo que vale como real, es meramente mi sueño o simplemente se halla en la conciencia.

48 Albert, op. cit., p. $3^{6}$. 
"falibilismo" con su "pragmatismo" de la certeza, en el sentido del "Critical Commonsensism", y apenas si logró esto satisfactoriamente. ${ }^{\text {} \theta}$ A mí me parece que los principios así confrontados pueden pensarse como consistentes cuando, y sólo cuando, se distingue entre el grado de reflexión de juegos lingüísticos precientificos y cientificos, por una parte, y, por otra, el grado reflexivo de una reflexión pragmático-trascendental sobre la estructura de juegos lingüisticos en general. (Aquí se trata, a mi juicio, no de una distinción, repetible cuanto se quiera, entre grados de reflexión conforme a la psicología o también a la jerarquía formal de los metalenguajes de la metalógica, sino de una distinción que, en lo posible, debe separar, inequivocamente y de modo reconocible en todo tiempo, la pretensión de universalidad, implicitamente autorreflexiva de los asertos filosóficos, frente' a la pretensión de validez individual a empírico-general de afirmaciones no filosóficas. ${ }^{50}$

Desde el punto de vista filosófico de la reflexión se puede entonces decir con referencia a cualquier juego de lenguaje en general -inclusive el filosófico-, que en su marco la duda y la crítica tienen sentido sólo bajo la suposición de que puedan fundarse suficientemente por medio de un recurso a evidencia paradigmática indubitable. Al mismo tiempo, empero, se puede formular en este plano de reflexión también una reserva falibilista, como duda virtualmente universal respecto de las evidencias paradigmáticas de todos los juegos de lenguaje posibles - excepto el filosófico de la duda. Con ella, naturalmente, son puestos fuera de función de modo virtual aun los juegos lingüísticos correspondientes - por decirlo así, en un experimento mental. Pues todo juego de lenguaje se mantiene en pie y cae, sin duda - según la concepción de Wittgenstein, sobre la cual también se apoya $T$. Kuhn en su análisis de las "revoluciones cientfficas"- junto con sus evidencias paradigmáticas. Sin embargo, la duda metacientifica, virtualmente universal, no es ninguna paper doubt en el sentido de Peirce. Pero esto sólo depende de que la reserva del falibilismo no formula aún ninguna pretensión de poner en duda por razones empíricas un aserto de la ciencia empírica, sino que en principio sólo abre esa posibilidad o la mantiene abierta. El mero abrir o mantener abierta la posibilidad de una duda fundada, y esto quiere decir,

49 Cfr., al respecto mi "Einführung" a Ch. S. Peirce, Schriften I, Frankfurt a. M. 1967, pp. 123 ss.

so Una teoría -un "modelo simbólico"_- de la reflexión, formalizable en el sentido de la lógica analitica de la ciencia, naturalmente no puede darse, como ha mostrado G. Frey contra las pretensiones de una objetivación total y una correspondiente simulación cibernética de la conciencia humana (Cfr. G. Frey: Sprache Ausdruck des Bewusstseins, Stuttgart 1965, pp. 37 ss., y del mismo: "Sind bewusstseinsanaloge Maschinen möglich?," en: Studium Generale, Jg. 19, 1966, pp. 191*200). Preclsamente esta concepción muestra, empero, que sin duda existe un saber filosófico-trascendental acerca de la diferencia básica entre cada grado imaginable de la jerarquía de los metalenguajes y el grado de reflexión de las proposiciones filosóficas - un saber que puede explicarse de manera teórico-filosófica. Cfr., a este respecto la explicación de la "autoestratificación" del espíritu y del lenguaje en Th. Litt: Denken und Sein, Stuttgart, 1948. 
de una crítica fundada, en el nivel metacientifico de reflexión no está, sin embargo, vacio de contenido, por cuanto funda el postulado metodológico del ensayo virtualmente universal de una critica fundada.

Bien puede decirse que este argumento hace valer el buen sentido, importante en teoría de la ciencia, del principio del falibilismo de procedencia peirciana y popperiana. Al mismo tiempo, sin embargo, nuestro argumento está en consonancia también con el punto de vista crítico-significativo y pragmático-trascendental de Peirce $\mathrm{y}$ Wittgenstein, de que la duda y la crítica, en el marco de un posible juego argumentativo, ya presuponen siempre la fundamentación por medio de evidencia fácticamente indubitable (iy por medio de la espera de una posible evidencial) como condición de su posibilidad. Con todo, a mi juicio, tiene que preguntarse expresamente por la razón de que -en virtud de lo dicho- tanto el principio del falibilismo, en el sentido de un principio de crítica virtualmente universal, como también el principio de fundamentación suficiente de la duda y la critica mediante recurso a la evidencia, sigan siendo válidos. En efecto, no es en manera alguna comprensible de suyo, sino extraordinariamente notable en lo filosófico que, por una parte, cualquier evidencia sobre la que se funda una doctrina cientifica, en principio puede y debe ser puesta en duda y criticada, mientras que, por otra parte, cualquier duda y cualquier crítica han de recurrir a evidencia indubitable $y$, en ese sentido, fundarse suficientemente. Una respuesta satisfactoria a la pregunta planteada aquí exige, a mi juicio, ni más ni menos que una adecuada distinción y mediación pragmático-trascendental entre la filosofía epistemológica del origen, de la época moderna, y la filosofia analitica del lenguaje, del siglo $\mathbf{x x}$.

En efecto, tanto como esto parece ser claro: si la filosofia epistemológica del origen (de procedencia empirista y a prióri) tuviera razón en su exigencia de reducir la validez intersubjetiva de verdad del conocimiento a (cualquier) evidencia de conciencia, no se podría entender en qué sentido convicciones evidentes pueden en general ser puestas en duda o criticadas. Por otra parte, si la lógica (proporcional-analítica) de la ciencia, orientada semánticamente, tuviera razón al suponer que las proposiciones sólo pueden ser fundadas por proposiciones y las evidencias de conciencia extralingǘsticas sólo pueden ser consideradas como motivos externos, causalmente eficaces para el establecimiento convencional de proposiciones base, entonces el punto de vista de que la crítica supone desde siempre una posible fundamentación mediante evidencia, sería ininteligible. Una reducción de este dilema me parece posible sólo bajo el supuesto (pragmático-trascendental) de que la evidencia de conciencia y la validez intersubjetiva de argumentos formulados lingüisticamente no son, por una parte, instancias de la problemática de la verdad reciprocamente reducibles; más, por otra parte, esas instancias, en 
cuanto tales, ya están siempre entretejidas entre sí de manera peculiar. Tratemos de explicar más exactamente esta tesis:

Por una parte, la evidencia de conciencia para mí (ya sea evidencia en el sentido de una intuición empírica, o en el de una ideal o categorial), contrariamente a la concepción de la gnoseologia moderna desde Descartes hasta Husserl, no puede en principio ser equiparada con la validez intersubjetiva de argumentos. La razón de esto se halla obviamente en la función mediadora del lenguaje, pasada por alto desde Descartes hasta Husserl, como condición trascendental de posibilidad de una interpretación del mundo intersubjetivamente válida. Una consecuencia de esta función mediadora parece ser, en efecto, que ya los juicios perceptivos —en el grado en que poseen un contenido de afirmación objetivo comunicable, el cual trasciende interpretativamente los datos sensibles subjetivos que la apoyan-, están sujetos a la posible critica en el sentido de una re-interpretación posible de las evidencias perceptivas indubitables en si. (Claro está que Kant postuló para la objetividad $e$ intersubjetividad de Ios "juicios de experiencia", en cuanto éstos trascienden a priori las evidencias de percepción meramente subjetivas, formas de enlace pre-lingüisticas y esquemas de toda "conciencia en general"; y la moderna "epistemología genética" de Piaget parece confirmar este postulado de manera empírico-psicológica. Pero estas condiciones de conciencia; postuladas por Kant como condiciones de posibilidad de una validez objetiva del conocimiento, no pueden, en primer término, como lo sabía Kant mismo, fundar inmediatamente la validez de los conocimientos empiricos de la ciencia; y en segundo término, desde la perspectiva de una pragmática trascendental del lenguaje, ha de exigirse que aún las proposiciones sintéticas a priori, evidentes de ese modo para Kant - y todavía para Husserl_, - por ejemplo, los axiomas de la geometrfa euclidiana o las proposiciones husser. lianas sobre el darse simultáneo, evidente a priori, de color y extensión-, sólo pueden ser principios de la ciencia intersubjetivamente válidos, por cuanto con base en convenciones tácitas fungen como evidencias paradigmáticas de la argumentación en determinados juegos de lenguaje. Mediante esa distinción y enlace de puntos de vista gnoseológicos y pragmático-lingüisticos, y a pesar del reconocimiento de ciertos enlaces de la representación, evidentes a priori, como condiciones subjetivas de posibilidad de una experiencia primaria - más o menos en el sentido de las "formas de la intuición" y de las categorías esquematizadas de Kant-, resulta posible, a mi juicio, poner en duda la validez intersubjetiva de los principios teóricos correspondientes - como los de la física clásica-, con base en una re-interpretación de la experiencia mediante teorías más capaces de explicación. Una pragmática trascendental del lenguaje conduce en ese sentido, a mi juicio, a la siguiente conclusión teórica de anti-evidencia: La respuesta a la pregunta por la validez intersubjetiva del conocimiento ya no puede ser dada mediante el 
recurso de los sujetos conocentes individuales a la evidencia de conciencia (así sea incluso una evidencia a priori para cada "conciencia en general"), sino sólo mediante la formación de consenso a base de un discurso argumentativo en la "comunidad de interpretación" de los científicos (Peirce, Royce). ${ }^{51}$

Por otra parte, sin embargo, el hablar de una elevación, posible y necesaria, de evidencias de conciencia a evidencias paradigmáticas de la argumentación en el marco de juegos lingüísticos, muestra que la formación de consenso en la comunidad de interpretación de los científicos a base del discurso argumentativo, en manera alguna puede ser pensada sin un recurso epistemológico a evidencias de conocimiento. Así, por ejemplo, es claro que aun las re-interpretaciones de nuestra experiencia primaria tienen que recurrir, a su vez, mediante teorías físicas con mayor capacidad explicativa, a una fundamentación suficiente por medio del recurso a evidencias paradig. máticas de juegos lingüísticos. Éstas, en cuanto lo son de teorías científicas, no necesitan poseer el carácter de evidencias inmediatamente intuitivas de la experiencia primaria. En el caso del espacio de Riemann, presupuesto por la teoría general de la relatividad, por ejemplo, se supone, obviamente en el sentido del espacio de la intuición, una evidencia paradigmática de juego lingüístico no comprobable como evidente. En este caso, sin embargo, el examen empírico de la teoría física tiene que llevarse a cabo con instrumentos de medida que suponen a su vez, respecto de su función y construcción, las evidencias presupuestas en el juego lingüístico "protofísico" de la geometría euclidiana en el sentido de la intuición ideal del espacio. Este ejemplo es adecuado, a mi juicio, para dilucidar el enlazamiento, necesario a priori, de la argumentación relacionada con el discurso y (la fundamentación suficiente por medio de) el recurso a la evidencia conocitiva: aun cuando la evidencia de conciencia individual no garantiza ya la validez intersubjetiva del conocimiento, con todo, la fundamentación argumentativa de la validez ha de remitir finalmente a tal evidencia en un juego de lenguaje científico, la cual en principio tiene que poder ser comprobada por todo miembro individual de la comunidad de interpretación, en última instancia mediante las evidencias de conciencia -empíricas o a priori- posibles para él. (Aquí debe observarse especialmente que la evidencia paradigmática, sobre la cual, en concepto de Wittgenstein, se tienen que apoyar la crítica y la duda en el marco de un juego lingǘstico, todavía no es idéntica a la evidencia conocitiva comprobada; más bien puede y debe ella recurrir in-

51 Cfr., mi articulo "Szientismus oder transzendentale Hermeneutik? Zur Frage nach dem Subjekt der Zeicheninterpretation in der Semiotik des Pragmatismus", en Hermeneutik und Dialektik, Festschrift für H. G. Gadamer, hersg. v. R. Bubner u. a., Tübingen, 197o, tomo I, ahora también en K. O. Apel: Transformation der Philosophie, loc. cit., tomo II. Cfr., a este respecto ahora la explicación de una teorfa de "discurso" y "consenso" de la verdad, que ha propuesto J. Habermas en "Wahrheitstheorien" (en Wirklichkeit und Reflexion, Festschrift f. W. Schulz, Pfullingen, 1974, pp. 211-265). 
mediatamente a convenciones, es más, sin la mediación de tales convencionos no podría en absoluto fungir como evidencia paradigmática de juego lingüistico, según hemos objetado con Wittgenstein contra Kant y Husserl. Pero las convenciones paradigmáticas de evidencia no pueden en cuanto tales de ningún modo ser reducidas a decisiones arbitrarias, sino que, en cuanto evidencias de argumentación, en último término se tienen que poder fundar - tan indirectamente como se quiera, por ejemplo, mediante el examen empírico de teorías apoyadas sobre ellas - con vistas a semejantes evidencias, que puedan comprobarse como interpretaciones manifiestas de evidencia de conciencia - empírica o a priori. A la circunstancia de que las evidencias de conciencia alcanzan validez intersubjetiva sólo en cuanto paradigmas de juegos lingüisticos reconocidos públicamente, corresponde, por tanto, en la perspectiva de la pragmática trascendental del lenguaje, la necesidad de un recurso argumentativo de fundamentación a la evidencia de conocimiento.)

Sin embargo, en la mediación pragmático-trascendental, señalada poco antes, entre filosofía de la conciencia y filosofía analítica del lenguaje, no se pretenderá en modo alguno reconocer todavía un argumento en favor de la fundamentación última. Más bien la fundamentación metacientífica del principio del "falibilismo" parece haber demostrado que todas las evidencias de conocimiento indubitables tienen que considerarse como relativas a determinados juegos de lenguaje, que en principio pueden ser trascendidos mediante la reflexión crítica. En el plano de reflexión sobre la validez, por tanto, parece que el principio de la critica (progresiva) puede mantener una superioridad básica sobre el principio de la fundamentación suficiente por medio del recurso a la evidencia. Las eventuales evidencias presupuestas por la argumentación en los juegos lingǘsticos particulares deben por principio considerarse como revisables; la crítica permanente, empero, por más que suponga en cada contexto particular un recurso a la evidencia, conserva -así parece- la última palabra en el plano de reflexión de la filosofía, que trasciende todos los juegos lingüísticos particulares.

En este lugar, sin embargo, debe pensarse que la circunstancia de que la crítica parece conservar la última palabra en el plano (metacientifico) de reflexión de la filosofía, está fundada obviamente en que se da algo así como un juego filosófico de lenguaje, en cuyo marco de antemano puede hablarse con pretención de validez universal sobre todos los juegos de lenguaje. (Wittgenstein intentó bagatelizar esta circunstancia, por cierto, mediante su tesis de la mera "semejanza" de familia de los "juegos" [de lenguaje]; ${ }^{32}$ y la dirección principal de la lógica analftico-lingüística de la ciencia, jurada sobre los nombres de B. Russell, R. Carnap y A. Tarski, tiene reparos fundamentales contra la implícita autorreferencialidad de la pretensión de validez uni- 
versal del discurso filosófico - reparos, naturalmente, que aun después de la teoría semántica de los tipos de Russell no pueden articularse con pretensión de validez universal de otra manera que en contradicción consigo mismos.s Con respecto al "racionalismo critico" de los popperianos, empero, es incontrovertible que su tesis sobre el anulamiento del postulado de fundamentación suficiente por medio del principio de la crítica, sólo puede fundarla sobre la pretensión de validez universal a priori de la argumentación filosófica.) Pero aqui se abre inmediatamente la perspectiva hacia un nuevo problema de fundamentación, el cual incluye el recurso a tales evidencias, que no puedan ser puestas en duda ni criticadas, por lo menos en la misma forma como lo son las evidencias paradigmáticas de aquellos juegos de lenguaje, que de antemano pueden ser considerados por la filosofia como revisables $y$, en este aspecto, como trascendidos. A la circunstancia, que parecía hablar en favor de la superioridad última de la crítica -es decir, la circunstancia de que la reflexión filosófica puede y tiene que entender como fundamentalmente revisables todas las evidencias paradigmáticas de juegos particulares de lenguaje-, corresponde ahora la circunstancia de que el mismo juego filosófico de lenguaje tiene que poder recurrir a evidencias que en principio no pueden ser equiparadas con ninguno de los paradigmas de juego lingüístico empiricamente revisables. Y esta circunstancia parece hablar más bien en favor de la superioridad de la fundamentación última que del principio de critica permanente.

4. Fundamentación última filosófica mediante reflexión pragmático-trascendental sobre las condiciones de posibilidad de la validez intersubjetiva de la argumentación filosófica

Antes de intentar en un último impulso mostrar efectivamente la indubitabilidad de ciertas evidencias paradigmáticas del juego lingüístico de la argumentación filosófica, quisiera yo primeramente aclarar que, y en qué sentido, el principio del falibilismo también debe aplicarse a argumentos filosóficos.

En primer lugar, aquí podría llamarse la atención sobre el hecho de que aun las deducciones lógico-matemáticas — dicho en forma trivial- son falibles, en cuanto que -consideradas con respecto a su dimensión pragmática como operaciones de hombres finitos_ pueden efectuarsé erróneamente. Más importantes que esta confesión empírico-pragmática es el punto de vista pragmático-trascendental, de que la demostrabilidad metalógica o metamate-

53 Cfr. M. Black: "Russell's Philosophy of Language", en P. A. Schilpp (ed.), The Philosophy of Bertrand Russell, Evanston, H. L., 1944, pp. 227-255, asi como antes, p. 12, sobre las introducciones "paralingülsticas" de una filosofía que se concibe a sí misma desde el paradigma de la semántica constructiva. 
mática de la exención de contradicción de sistemas lógico-matemáticos axiomatizados es fundamentalmente imperfecta. En lo anterior nosotros hicimos valer esta circunstancia, siguiendo a $\mathrm{H}$. Lenk, como un aspecto del "trilema de Münchhausen" de la fundamentación última deductiva, pero al mismo tiempo señalamos que el problema filosófico de la fundamentación última pör ese hecho es más bien planteado que llevado ad absurdum. En el actual contexto, pues, tenemos que reivindicar el conocimiento sobre la imperfección fundamental de todas las pruebas de exención de contradicción ya como un conocimiento reflexivo, filosófico-trascendental de las condiciones de posibilidad y los limites de la objetivación de argumentos en sistemas lingüísticos axiomatizados y formalizados. $Y$ es difícil de imaginarse cómo ese conocimiento propio de una ampliada crítica de la razón debería poder ser revisado en su núcleo filosófico-trascendental. Por supuesto, no se sabe jamás dëfinitivamente qué pertenece aqứ al núcleo filosófico-trascendental y qué -mediante los progresos de la metamatemática o de la metalógica- al complejo de resultados revisable. En ese sentido ya la interpretación pragmáticotrascendental de los resultados de la metalógica o de la metamatemática puede dar un indicio sobre la situación del problema, modificada con relación a Kant, de la filosofía trascendental: la exigencia kantiana de perfección definitiva de un "sistema de la razón pura" no puede aqú́ sostenerse; más bien se trata de un descubrimiento reflexivo-progresivo de horizontes trascendentales, que se amplian en la medida en que también se amplía el conocimiento humano, al que debe interrogarse por sus condiciones de posibilidad. Sin embargo, de estas reflexiones no se sigue en manera alguna que el principio del "falibilismo" y el derivado de éste de una critica virtualmente universal, pudieran llevar ad absurdum o sustituir el postulado de una fundamentación última filosófico-trascendental.

Que esto es imposible, resulta ya del solo hecho de que la autoaplicacion del principio del "falibilismo" conduce manifiestamente a una paradoja, que es análoga a aquélla del "mentiroso": si el principio del "falibilismo" es él falible, entonces en ese sentido precisamente no es falible y a la inversa. Ahora bien, la autoaplicación del principio del "falibilismo" no puede, por ejemplo, ser rechazada como sin sentido por los representantes del "racionalismo crítico"; pues precisamente ellos son, sin duda, los que absolutizaron el principio metodológico del "falibilismo", relacionado originariamente con las ciencias empíricas. De ahí se sigue, a mi juicio, con toda la claridad deseable, que el "racionalismo pancrítico" representa un punto de vista insostenible -o al menos una exageración. El principio del "falibilismo" o el principio de la crítica, derivado de él, pueden tener sentido y validez obviamente sólo cuando de antemano son restringidos con relación a su validez en tal forma, que por lo menos aquella evidencia filosófica, sobre la que ellos mismos han de fundarse, de antemano es exceptuada de la posible crítica. Ahora 
bien, con ello la dimensión pragmático-trascendental de las condiciones de posibilidad no criticables de una critica y autocrítica filosóficas intersubjetivamente válidas queda abierta en una forma suficientemente radical: ¿Qué pertenece a esas condiciones? En esta pregunta se concentra, a mi juicio, el problema de la fundamentación última filosófica.

Que el principio del "racionalismo pancrítico" no pertenece a las condiciones no-críticas de posibilidad de una crítica filosófica, se puede documentar de manera interesante con la exitosa autocrítica del "racionalismo pancrítico" en su fundador, W. W. Bartley. Éste, en efecto, comprobó que la lógica manifiestamente "no puede pertenecer a aquella totalidad que debe ser sometida a prueba", puesto que "el ejercicio de una discusión crítica y la lógica están ligadas inseparablemente." $\$ 4$ En su confrontación crítica con Bartley y Albert, Hans Lenk precisó la comprobación del primero en el sentido de "que por lo menos algunas reglas lógicas están fundamentalmente eximidas de revisión racional". ${ }^{55}$ Aún más interesante me parece ser la indicación de Hans Lenk de que las aludidas reglas de una lógica mínima están a priori exentas de crítica, porque se hallan ligadas "analiticamente" con la (idea de la) institución de la critica misma. ${ }^{68}$ Con ello -así me parece-, por el camino metódico no de deducción logico-formal de principios, sino de reflexión pragmático-trascendental sobre las condiciones de posibilidad de una argumentación crítica, quedó descubierto precisamente aquel "juego trascendental del lenguaje" como "institución de la crítica", del cual vale en sentido enfático el punto de vista citado antes del Wittgenstein último: que es como un "sistema... a cuya esencia pertenece lo que nosotros llamamos un argumento", es por decirlo asi, "como la materia vital de los argumentos".st

El despejo pragmático-trascendental de este "sistema" de la argumentación, se muestra como fundamentación última filosófica por un camino no deductivo, en cuanto que sus evidencias paradigmáticas son exactamente aquellas que no pueden ni ser puestas en duda por la crítica sin autocontradicción, ni ser fundadas deductivamente sin presuponerse a sí mismas. La discusión hoy usual, orientada hacia sistemas axiomáticos de la lugica, del problema de la fundamentación última acostumbra, naturalmente, interpretar esta situación de otra manera: a saber, en el sentido de que las evidencias últimas no pueden ni ser impugnadas sin autocontradicción, ni ser fundadas sin petitio principii. Según esto - asł́ se dice- la fundamentación última tiene que ser sustituida por una decisión última, más o menos en el sentido de la confianza en sí misma de la razón contra el escepticismo (así, por ejemplo,

54 W. W. Bartley, Flucht ins Engagement, München, 1964, pp. 180 ss.

58 H. Lenk, op. cit., pp. $105 \mathrm{~s}$.

50 Id., p. 107 .

57 L. Wittgenstein: Ober Gewissheit, Aphorismus 105, cfr, antes, p. 44 . 
W. Stegmüller) ${ }^{58}$ o en el sentido de la pertenencia a la institución de la discusión crítica contra el oscurantismo (asi, por ejemplo, K. Popper). ${ }^{59}$ (Esta "solución" del problema de la fundamentación última obviamente corresponde de nuevo al "trilema de Münchhausen" - deducido en forma puramente lógica- de la fundamentación última según Hans Albert, si se prescinde de que W. Stegmüller entiende el "recurso a la evidencia" no como "recurso a un dogma", sino como una necesidad de todo filosofar, que no puede impugnarse sin autocontradicción y cuya satisfacción ciertamente no puede ser demostrada sin petitio principii.)

A la luz de nuestra reflexión pragmático-trascendental, sin embargo, la evaluación, presupuesta aquí, del estado del problema se muestra una vez más como absolutización (ilegitima) de lo objetivo y desprendido (enajenado) - presupuesto juntamente con el método axiomático- de la argumentación, en proposiciones y sistemas proposicionales interpretados de manera sintdctico-semántica, en cuyo análisis se abstrae siempre de la dimensión pragmático-trascendental -autorreflexiva- del sujeto que argumenta. La semántica lógica de las proposiciones y los sistemas proposicionales, empero, sólo puede ofrecer - como ha visto Y. Bar-Hillel— ${ }^{60}$ un esclarecimiento "indirecto" de la argumentación en el lenguaje ordinario, integrado fundamentalmente de modo pragmático; es decir, un esclarecimiento con base en una abstracción de la dimensión pragmática, la cual debe fundamentalmente anularse, si el sentido de los sistemas axiomáticos ha de ser rescatado para la argumentación. Por ello, la restricción del concepto de fundamentación última en el sentido de la deducción de proposiciones a partir de proposiciones (o también en cuanto demostración metalógica de exención de contradicción en sistemas proposicionales), me parece apoyarse en último término sobre una "abstractive fallacy"; - dicho más exactamente: sobre aquella "abstractive fallacy", que sirve de base a toda la lógica de la ciencia de nuestro tiempo, orientada en forma puramente sintáctico-semántica, en cuanto que ella remite a la competencia de la psicología empírica la dimensión pragmática no formalizable de la argumentación- por ejemplo, la responsable autorreflexión de los que argumentan, como se expresa en los actos realizativos de afirmación. El hablar de la imposibilidad de la fundamentación última filosófica se muestra en ese aspecto como consecuencia de confundir la argumentación originaria, ligada al diálogo en forma de afirmación y réplica, sobre la cual Sócrates quiso fundar el filosofar, con la "apodíctica", instituida por Aristóteles, que únicamente puede ser "un órgano" de la argumentación, purificado de even-

s8 W. Stegmüller: Metaphysik, Skepsis, Wissenschaft, $2^{\mathrm{a}}$ ed. Heidelberg-New York, 1969, p. 169 .

59 Así K. Popper, Die offene Gesellschaft und ihre Feinde, Bern 1958, t. 2, pp. 110 s. 60 Cfr., antes nota 33 . 
tuales elementos pragmáticos perturbadores." Ahora bien, si esa "abstractive fallacy" -en el sentido de admitir una reflexión pragmático-trascendental sabre las condiciones subjetivo-intersubjetivas de posibilidad de una argumentación intersubjetivamente válida - es anulada, entonces el problema de la fundamentación última se muestra en una luz del todo cambiada: el conocimiento de que ciertas evidencias no pueden fundarse deductivamente, sin tener ellas mismas que ser presupuestas - por ejemplo, la evidencia paradigmática de una lógica mínima en el marco de un juego lingüistico trascendental, aún por explicarse con más exactitud, de la argumentación crítica-, ese conocimiento se manifiesta ahora, no como prueba de la imposibilidad básica de una fundamentación última filosófica, sino como inteligencia reflexiva, pragmático-trascendental, de los fundamentos no criticables de la argumentación misma: si yo no puedo impugnar algo sin autocontradicción real y al mismo tiempo fundarlo deductivamente sin petitio principii lógicoformal, entonces éste pertenece precisamente a aquellos supuestos pragmáticotrascendentales de la argumentación, que uno tiene que haber reconocido siempre, si el juego lingüístico de la argumentación ha de conservar su sentido. Por tanto, esa manera de argumentar pragmático-trascendental puede llamarse también la forma crítico-significativa de la fundamentación última.

En cuanto yo veo, esta forma pragmático-trascendental-reflexiva de la fundamentación última filosófica, prueba su eficacia tanto en el sentido crítico como en el afirmativo, al reconstruir la argumentación de la duda cartesiana.

Asi, por ejemplo, se puede mostrar que Descartes destruye el posible sentido del juego lingǘstico, a que él recurre de manera irreflexiva, cuando en el desarrollo de su duda metódica supone que al final todo lo que vale como real, es meramente su sueño, es decir, existe sólo en la conciencia: si todo lo que vale como real, es meramente un sueño, es decir, existe sólo en la conciencia, entonces precisamente el sentido crítico de la expresión "meramente un sueño" (o "sólo en la conciencia") no puede sostenerse, pues presupone, como evidencia paradigmditica de juego lingüistico, que no todo es meramente un sueño (o existe sólo en la conciencia). Este pseudoargumento, que a ojos

61 Un testimonio interesante de un temprano anticipo de esta confusión y de la reducción moderna de la filosofia a una semántica lógica, es el siguiente texto que el comentador

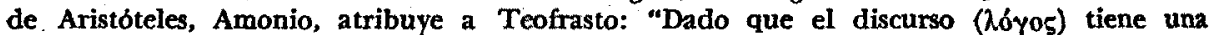
doble referencia... una a los oyentes, para quienes tiene una significación, y otra a las cosas, sobre las que quien habla pretende inculcar una convicción a los oyentes, surgen en vista de la referencia a los oyentes, la poética y la retórica...; por la referencia del discurso a las cosas, empero, el filósofo es el que preferentemente debe preocuparse, al refutar lo falso y demostrar to verdadero." La lógica del lenguaje del empirismo lógico ha renovado esta división, al poner en lugar de la poética y la retórica la pragmática empirica. Sin embargo, como a la moderna filosofía analitica del lenguaje precedió la filosofía trascendental del sujeto conocente, nosotros los actuales tendriamos que estar en situación de ver que esa división es incompleta. El completarla, naturalmente, no puede emprenderse mediante una filosofla trascendental de la conciencia, la cual -como Kant- remite el discurso en general a la "antropología en sentido pragmático". 
vistas se apoya sobre la ilegítima abstracción -que Descartes hace en la búsqueda metódico-solipsista de la evidencia del a priori de juego lingüístico de la argumentación - y con ello también del pensar aún tan solitario-, puede, sin embargo, como se indicó ya en lo anterior, ser corregido con Peirce y Popper en favor de una duda virtualmente universal, es decir, del principio del falibilismo. Si se echa mano de esta corrección, entonces el auténtico significado de la duda cartesiana se manifiesta en la circunstancia de que no puede dudarse de la certeza del "dubito, cogito, ergo sum", aun en el sentido de la duda virtualmente universal de todo lo que vale como real. ¿Sobre qué se apoya, entonces, esa certeza del "cogito, ergo sum"?

No puede apoyarse, como ha mostrado J. Hintikka en 1969 con los medios conceptuales de la teoría del acto de hablar de Austin, ${ }^{62}$ sobre el hecho de que (en el sentido de la semántica lógica) fuera permitida una conclusión silogistica de lo que se piensa a su existencia. Aun Descartes mismo rechazó, sin duda, muchas veces tal interpretación; pero Hintikka menciona expresamente la causa por qué no es admisible ella: en una conclusión silogística de lo que se piensa a su existencia, tendría que presuponerse siempre en forma tácita la existencia del que piensa, a fín de poder excluir como no importante el pensar de personas ficticias - como por ejemplo, la de Hamlet. Con otras palabras: demostrar de modo lógico-formal precisamente la certeza del cogito, ergo sum, no es posible. En este sentido no se da en Descartes ninguna fundamentación última, que pudiera reconstruirse afirmativamente. Que aquel que piensa, existe, es más bien, vista de modo lógico-formal, una tesis que, en el sentido del dilema de Stegmüller, no puede ni negarse sin autocontradicción, ni demostrarse sin petitio principii. Pues, sin duda, no podría ser hecha válida por una persona ficticia, como Hamlet, sino sólo por un pensador existente. Mas, justo por ello, la certeza del ego cogito, ergo sum en el sentido de nuestra tesis, es una condición pragmático-trascendental de posibilidad del juego lingüístico de la argumentación. ¿Hasta qué punto se puede mostrar esto? Que mi dudar o pensar asegura mi existencia, depende -como muestra Hintikka- de que yo, mediante el acto realizativo del dudar de mi existencia —el cual puede formularse de manera explícita en la proposición: "Mediante esto que digo, dudo (ahora) de que existo"-, refuto ante $\mathrm{m}$ í mismo -y virtualmente ante cualquier compañero de diálogo- ${ }^{63}$ el sentido de la proposición afirmado así. La certeza irrefutable del cogito, ergo sum se apoya (por tanto) no sobre un contexto proposicional deductivo, axiomáticamente objetivable, sino sobre una inteligencia reflexiva pragmático-trascendental, proporcionada por la autorreflexión actual del acto de pensar o hablar.

o2 Cfr. J. Hintikka: "Cogito, Ergo Sum: Inference or Performance", en: Philos. Review, 71 (1962), pp. 3-32.

63 De modo muy análogo muestra $W$. Stegmüller, mediante el acto realizativo con el 
Hintikka advierte, por lo demás, que no sólo la afirmación: "Yo no existo", es refutada por el acto de pensar o hablar, que la realiza, sino igualmente la afirmación "Tú no existes". En efecto, quien -así explicaría yo esto- empleara semejante forma de hablar, por ejemplo frente a la aparición de un fantasma, como conjunto, en realidad no le negaria la existencia a un objeto en un acto de predicación, sino que anularía más bien la forma de hablar de tú, y ello querría decir, designaría reflexivamente su acto de comunicación como fracasado. En esto yo vería un indicio de que la certeza irrefutable del ego cogito, ergo sum se apoya no precisamente, como se suponía hasta Brentano en la tradición cartesiana de la teoría de la evidencia, sobre el primado de la llamada "experiencia interna" o "introspección" de la conciencia, fundamentalmente solitaria, sino sobre el primado de una experiencia de situación a la vez comunicativa y reflexiva, en que la actual comprensión de sí mismo ( $y$ con ella la conciencia del yo) y el comprender la existencia de los otros son igualmente originarios - como de hecho es sostenido en forma coincidente por G. H. Mead y por M. Heidegger. La convicción sobre la propia existencia en el ego cogito, ergo sum, entendida en forma realizativa, sólo es posible como un entendimiento consigo mismo sobre sí mismo, y esto quiere decir: como parte de un diálogo virtualmente público; dicho con mayor exactitud: como modo deficiente de un diálogo tal, que en él yo soy para mí mismo el otro. Precisamente esto se prueba en que la certeza reflexiva de sí mismo puede hacerse explícita con ayuda de un acto de hablar realizativo.

Por ello, la certeza del cogito, sum no puede, como pretende E. Husserl en las Meditaciones cartesianas, ser entendida de manera que no sea posible ya formularla en un "plural comunicativo". Pues en semejante epoje del "solipsismo metódico", en la que junto con el mundo real estaria entre pa-

cual reclama validez para su tesis de "que el problema de la evidencia es aboslutamente insoluble" (op. cit., p. 168), que la existencia de la evidencia es una condición necesaria de posibilidad para un argumentar con sentido. Esto no contradice naturalmente su comprobación, de que la existencia de la evidencia no puede ser demostrada (es decir, deducida lógicamente) sin un círculo lógico; pero muestra que restringir el problema de la fundamentación a la posibilidad de la demostración lógica en el marco de un sistema proposicional sintáctico-semántico objetivado, puede desembocar en una "abstractive fallacy", cuando de lo que se trata es del problema filosofico de la fundamentación última. Finalmente, en efecto, Stegmüller tampoco puede evitar penetrar en el campo de la pragmática (trascendental). Lo cual hace al concluir que el sujeto argumentante es forzado a una "decisión de conciencia prerracional", ante el dilema de que la existencia de la evidencia no puede ser impugnada sin autocontradicción ni demostrada sin petitio principii. Este salto a la dimensión pragmática, sobre el que no se reflexiona de manera pragmático-trascendental, necesìta, sin embargo, pasar por alto que el conocimiento reflexizo sobre que la existencia de la evidencia es una condición de posibilidad del argumentar - la cual no puede ser impugnada sin autocontradicción, ni demostrada lógicamente sin petitio principii-, en cuanto conocimiento de la situación pragmática del que argumenta, hace del todo superflua una decisión prerracional en favor de la suposición de la evidencia.

64 Cfr. E. Husserl: Cartesianische Meditationen, Den Haag, $2^{\text {a }}$ ed. 1963, p. $5^{8}$. 
réntesis en principio también la existencia de otros sujetos, la evidencia de la visión cartesiana ciertamente no podría en principio ser formulada en el sentido de un juicio filosófico intersubjetivamente válido. De hecho, Husserl no podría en absoluto darnos a conocer el resultado de su reducción o epojé trascendental - la visión evidente para él de la imposibilidad de suprimir la esfera de la conciencia del yo puro, noético-intencional y constitutiva de sentido, así como de sus correlatos de acto noemáticos-, si no pudiera él formular precisamente esto en un "plural comunicativo": "Cada uno de nosotros es capaz de entender con evidencia subjetiva y con pretensión de validez a priori intersubjetiva, que no puede sin autocontradicción actual dudar de la existencia de su yo." " no podría - como tampoco ya Descartes - hacer consciente ni siquiera a si mismo la indubitabilidad de su conciencia del yo en una forma comprensible y válida para ell, si no pudiera siempre formular esa visión como argumento en el marco de un juego trascendental del lenguaje y en esa forma hacerla valer ante sí mismo como el representante de una comunidad ideal de comunicación. En suma: como "fundamentum inconcussum", en el sentido de la tradición cartesiana reconstruida y transformada críticamente, de la fundamentación última filosófica, debe presuponerse junto a la conciencia del yo un juego de lenguaje, en el que con la evidencia actual del yo me pienso como existente, en el sentido de una evidencia paradigmática de juego lingüistico, se presupone a la vez la existencia de un mundo vital real y la de una comunidad de comunicación, en la que aquella visión cartesiana tiene que poder ser conocida, examinada y —en ese caso-, confirmada. Este enfoque pragmático-trascendental de la visión cartesiana como de un juicio evidente a priori y al mismo tiempo válido a priori intersubjetivamente, tendráa validez en principio incluso para el último hombre solitario, vistas las cosas empíricamente: aún él tendría que presuponer: 1) que ha habido una comunidad real de comunicación, 2) que una ilimitada comunidad ideal de comunicación tendria que poder comprobar la evidencia de su visión. ${ }^{86}$

65 Atiéndase a la inseguridad de Husserl en la siguiente formulación (op. cit, p. 6o): “... esta ė $\pi 0 x \eta ́$ fenomenológica, o este poner entre paréntesis el mundo objetivo..., no nos [subrayado mío] coloca, por tanto, frente a la nada. Lo que más bien se nos [subrayado mio] hace nuestro, y precisamente por ello; o con más claridad: lo que a mí, que medito, se me hace por ello mio, es mi vida pura con todas sus vivencias puras y todas sus vulgaridades puras, el universum de los fenómenos en el sentido de la fenomenologia."

66 Cuando Husserl aclara: "Yo no puedo vivir, experimentar, pensar, valorar y obrar dentro de ningún otro mundo sino aquel que en $\mathrm{mi}$ y por mí mismo tiene sentido y validez", ve él a través del a priori (de juego) lingüístico de su pensamiento, en cierta forma como a través de un cristal -no de otra manera que como Descartes al principio de la época de una filosofia fundada sobre la evidencia de la autoconciencia. Cuando, naturalmente, toda esta época, a causa de su reflexión sobre las condiciones subjetivas de posibilidad de una evidencia conocitiva, se rechaza como extravio - como lo ha hecho muy recientemente $W$. Becker, que con ello causa en cierta medida una destrucción de la historia de la filosofía trascendental, desde la perspectiva del "racionalismo crítico" (cfr. W. Becker, 
En resumen: el "elemento vital" de los argumentos filosóficos es un juego trascendental de lenguaje, en el que junto con algunas reglas de la lógica se suponen la existencia de un mundo real y las reglas pragmático-trascendentales de la comunicación ideal. Aun en el pensar solitario, el individuo puede asegurar su existencia como cierta a priori ante sí mismo, sólo con relación a ese juego trascendental de lenguaje y a sus evidencias paradigmáticas. Pero esto significa: el individuo no puede entrar en la "institución" de este juego lingüistico trascendental de la argumentación crítica, o salir de ella, del mismo modo que se presupone esto en los "juegos de lenguaje" empíricos y en las "instituciones" como "formas de vida" (Wittgenstein). ${ }^{67}$ Más bien, en cuanto "homo sapiens" exitosamente socializado y provisto de competencia comunicativa, ${ }^{68}$ tiene por necesidad la constitución de un ser que siempre se ha identificado en forma de esbozo con la comunidad ideal de comunicación y ha reconocido implícitamente las reglas pragmático-trascendentales de comunicación. A esto no contradice la circunstancia de que en todo tiempo nosotros nos podemos hacer conscientes de la discrepancia entre el ideal normativo de la comunidad ideal de comunicación y las situaciones reales de diálo-

Selbstbewusstsein und Spekulation. Zur Kritik der Transzendentalphilosophie, Freiburg, 1972)- entonces con ello, a mi juicio, el niño es vaciado junto con la bañera. Pues no es la voluntad de evidencia o el "modelo de reflexion" (W. Becker) los que deben rechazarse desde el punto de vista de la discusión critica, sino el confundir la reflexión sobre la validez con el conocimiento genuino de una especial esfera del ser (así en Descartes y todavia en Husserl), o tal vez con el conocimiento sustancial en general (así parcialmente en el idealismo alemán), y el confundir la evidencia actual (para mi conciencia) con la validez inter. subjetiva del conocimiento. Estas confusiones, empero, pueden -como me parece- ser evitadas o desenredadas mediante una pragmática trascendental del lenguaje. Para una convincente investigación de la aportica husserliana, cfr. tambin $H$. Röttges: "Evidenz und Solipsismus in Husserls 'Cartesianischen Meditationen'", en W. F. Niebel/D. Leisegang (Hrsg.), Philosophie als Beziehungswissenschaft, Festschrift für J. Schaaf, Frankfurt a. M. 1971.

67 En ese aspecto, no sólo tengo que completar, sino todavía más, "dramatizar" de manera filosófico-trascendental - para emplear un término de H. Albert- la caracterización de Hans Lenk de las reglas no criticables de la "institución de la critica racional". "Reglas e ideas (o instituciones)" de la critica racional, a mi juicio, no sólo están "acopladas unas a otras mediante convenciones de lenguaje" (Lenk, op. cit., p. 108), sino que la convención lingǘstica es en este caso sólo "realización convencional" de reglas, que ante todo hacen posibles la convenciones explícitas ("convenios"). Más claramente: idea e institución de la crítica racional no son una forma vital historica entre otras formas vitales posibles, por más que en la forma familiar a nosotros sólo hayan sido fundadas, es decir, realizadas convencionalmente, por los filósofos griegos. Bien puede ser que la institución de la discusión racional haya contribuido a la realización del "homo sapiens", mas pudo hacer esto, obviamente, solo porque hizo explícitas unas respecto de otras las últimas condiciones de la interacción significativa de todos los hombres - y de todas las formas de vida humanas. En todo caso, hoy la situación es que "la idea de la crítica racional" no sólo no puede renunciar a sí misma (Lenk, op. cit., p. log), sino que tampoco nosotros podemos renunciar a ella, sin renunciar a nosotros en cuanto hombres _-en un sentido no patológico. Con esto, naturalmente, no se significa que todos los hombres tuvieran que ser filosofos (en el sentido académico) o tal vez partidarios del racionalismo critico".

68 Cfr. J. Habermas, "Vorbereitende Bemerkungen zu einer Theorie der kommunikativen Kompetenz", en J. Habermas/N. Luhmann, Theorie der Gesellschaft oder Sozialtechnologie, Frankfurt a. M. 1971, pp. 101-141. 
go. Más bien, como me parece, precisamente ahí -es decir, en el a priori de la comunidad de comunicación, presupuesto por la argumentación racional, o más exactamente: en la contradicción, que no puede resolverse de manera lógico-formal, entre el supuesto de la comunidad real de comunicación (inclusive nuestro yo real) y la situación, "anticipada" ahí "contrafácticamente" en forma necesaria, de una comunidad ideal de comunicación - se halla un indicio de la posibilidad de encontrar también los supuestos de una "fundamentación última" pragmático-trascendental de la ética. ${ }^{69}$ En tal sentido la "institución" del juego trascendental de lenguaje se muestra como muy diversa de las instituciones, que se apoyan sobre convenciones, de los "juegos de lenguaje", capaces de ser descritas empíricamente, o de las "formas de vida" en el concepto de Wittgenstein. ${ }^{70}$ Más bien podría ella ser caracterizada como metainstitución de todas las instituciones humanas posibles, ${ }^{71}$ puesto que abarca las condiciones de posibilidad de convenciones transparentes y racionales ("convenios"). El hombre puede separarse de esta institución, sólo al precio de perder la posibilidad de su autoidentificación como un ser que obra con sentido - por ejemplo, en el suicidio por desesperación existencial o en el proceso patológico de la pérdida paranoico-autista de sí mismo. .

Por esto - para sacar una última consecuencia_, en el sentido pragmático trascendental no puede uno decidirse por esa forma de vida racional en una "elección irracional", según pretende Popper; ${ }^{72}$ pues una elección que se concibe a sí misma como significativa, presupone ya el juego trascendental de lenguaje como condición de su posibilidad. Sólo bajo el supuesto racional de reglas que pueden cumplirse intersubjetivamente, se puede, en efecto, entender la decisión en vista de alternativas como un obrar pleno de sentido. De ahi no se sigue que cada decisión sea racional, pero si que la hecha en favor del principio de una legitimación racional o de una critica del obrar conforme a reglas a priori, es racional. En ese aspecto, la decisión exigida por Popper en favor del llamado "marco" de la argumentación o discusión crítica, puede ahora ser entendida como corroboración volitiva, racional a priori, de las reglas del juego trascendental de lenguaje, reconocidas como vdlidas. Una decisión semejante -e incluso siempre renovada, especialmente en las "situaciones existenciales extremas" de la vida — es ciertamente indispensable

69 Para un ensayo de realización de este programa, cfr. mi artículo "Das Apriori der Kommunikationsgemeinschaft und die Grundlagen der Ethik", en Transformation der Philosophie, tomo II, op. cit., pp. 358-435. AhI (pp. 397 s.) hay también objeciones contra la propuesta albertiana (cfr., antes p. 4), de tratar los sistemas morales que compiten como teorias de la ciencia empiricamente fasificables. Una actitud semejante presupone ya de hecho una norma ética fundamental.

$70 \mathrm{Cfr}$. mi articulo "Die Kommunikationsgemeinschaft als transzendentale Voraussetzung der Sozialwissenschaften", en: Transformation der Philosophie, tomo II, loc. cit.

71 Cfr. mi artículo "Arnold Gehlens 'Philosophie der Institutionen' und die Metainstitution der Sprache", op. cit., tomo I.

72 Cfr. antes nota 59. 
en interés de la realización de la razón..$^{78}$ Pero de ningún modo necesita ella sustituir su jústificación racional, en el sentido del decisionismo, por una decisión. Pues siempre puede asegurarse de su propia legitimidad mediante reflexión sobre la circunstancia de que ella presupone ya, para la comprensión de sí misma, las reglas por las que vota. La afirmación de Popper, de que el irracionalismo puede ser defendido sin contradicción, porque puede rehusarse la aceptación de argumentos, ${ }^{74}$ es sencillamente falso, pues el defender el irracionalismo contradice actualiter - es decir, en virtud del acto realizativo inherente- la tentativa de rechazar la argumentación. El rechazo efectivo de la argumentación racional -o de la correspondiente autocomprensión- es, por otra parte, un asunto más serio de lo que Popper parece sospechar: es un acto de autonegación y -en la última consecuencia- de autodestrucción, como ya he indicado. ${ }^{75}$ Pero, aun en un caso semejante, quien se decide tiene que presuponer el principio negado mientras comprende su propia decisión en cuanto tal. De otra manera, el decisionismo filosófico (sobre el cual el "racionalismo crítico" apoya, en última instancia, su argumentación) no podría hacer referencia al acto de rechazo de la razón como una posibilidad comprensible de decisión humana.

Con esto, puedo compendiar el resultado de mi intento de una metacritica del "racionalismo crítico": éste no puede -así me parece a ml- tener éxito en poner el principio de la critica en cuanto tal en lugar del principio de la fundamentación última filosófica, porque su critica a este principio

73 En este aspecto la referencia de Popper a la tradición voluntarista desde Duns Scotus hasta Kant (Die offene Gesellschaft..., I. c., p. 289 , nota 6) está justificada, y por cierto en virtud de que el engagement de la voluntad en favor de la realización de la razón, no es precisamente del mismo valor que el sustituir una autojustificación mediante un decisionista "Sic volio, sic jubeo; stet pro ratione voluntas". Este punto de vista, sin embargo, tiene que hacerse valer, según me parece, no sólo contra el decisionismo de Popper, sino también contra la argumentación de Habermas en "Legitimationsprobleme im Spätkapitalismus" (op. cit., p. 152, nota 405 ). Es cierto que yo coincido plena y totalmente -como apenas si necesito acentuarlo- con la teoria de Habermas, de que nosotros hombres, no sólo como argumentantes, sino también ya como operantes, hemos reconocido siempre en forma implicita la validez de las normas de comunicación ideal mediante anticipación contrafáctica de una situación comunicativa ideal. Sin embargo, me parece necesario facilitar la reflexión trascendental sobre ese "factum de la razón" mediante la reflexión de los que argumentan sobre las condiciones de posibilidad de su praxis. Pues solo a partir del argumento las condiciones de posibilidad de todo obrar con sentido pueden hacerse explicitas en el marco de juegos lingülsticos. Pero, más importante que este punto de vista metódico, es la circunstancia de que la reflexión sobre el "haber-reconocido-ya-siempre-de-modo-necesario" los principios éticos no descarta la necesidad de una corroboración volitiva - siempre renovada- de ese reconocimiento en el sentido de un engagement para la realización de la razón. Esta exigencia, a mi juicio, no desemboca en un "resto de decisionismo", sino en el acto de hacer valer la indispensable función de la buena voluntad en el sentido de una unidad ética de conocimiento e interes.

${ }^{74}$ Cfr. K. Popper, Die. offene Gesellschaft und ihre Feinde, loc. cit, p. 284 .

${ }^{75}$ Las decisiones contra la realización de la razón no significan, por regla general, una negación básica de las reglas pragmático-trascendentales del discurso racional. Por el contrario: sólo se recurre excepcionalmente a una dispensa - ¡de ello vive el diablol 
-como toda crítica con sentido - necesita ella misma de justificación. Pero esa justificación del principio de la crítica es posible precisamente cuando, y sólo cuando, el principio no se pone él en forma absoluta, sino que se restringe a sí mismo mediante el principio de autofundamentación de la razón crítica a través de reflexión trascendental ${ }^{78}$ sobre sus condiciones de posibilidad. Lo más notable de la fundamentación última filosófiça se halla entonces en el argumento reflexivo - pragmático-trascendental y no deductivo-, de que no se puede razonar o decidirse prácticamente ni en favor ni en contra de las reglas del juego trascendental de lenguaje, sin presuponer ya esas reglas.

KARL-OTto APEL

[Trad. de Bernabe Navarro]

UNIVERSidAd DE Frankfurt

78 Que todo depende; decisivamente, del movimiento ideológioo de la reflexión trascendental, lo muestra en forma muy interesante el dilema de un constructivismo puro en el caso de la Escuela de Erlangen. Aunque Paul Lorenzen quisiera resolver el problema de la fundamentación última en el sentido de una reconstrucción de la filosofía trascendental kantiana, sin embargo, cree él tener que admitir, que en el comienzo ha de haber un "act of faith", porque "the term 'justification' makes sense only after one has accepted... principles" (Normative Logic and Ethics, Mannheim/Zürich 1969, p. 74). Esta situación del problema, que obviamente es análoga a aquella de $\mathrm{K}$. Popper, se presenta, sin embargo, a mi juicio, sólo cuando la reflexión trascendental sobre los principios, que uno tiene que haber aceptado siempre de manera necesaria, no es reconocida ya como paso en el juego filosófico de la argumentación, o simplemente se pasa por alto tal posibilidad. Esto me parece ser en verdad una violencia mental típicamente moderna: se quiere practicar la inversión copernicana de Kant y se empieza enseguida con un movimiento constructivo. Mas, para poder disponer la construcción lógica como reconstrucción de nuestras competencias, tenemos que reflexionar primero sobre aquello más allá de lo cual ya no puede irse, esto es, las condiciones de posibilidad de una crítica válida, implícitas en el juego trascendental de lenguaje. Sólo este movimiento de reflexión filosófico-trascendental nos preserva, por una parte, del relativismo de "framework", fundado de manera decisionista y, por otra, de una absolutización naturalista de la autorreflexión, puesta en evidencia empiricamente - por ejemplo, en forma critico-ideológica (en el sentido de los reduccionismos del "nada sino" del siglo xrx)_-Cfr., para la distinción entre reflexión trascendental y autorreflexión critica también el "Apéndice" de J. Habermas a la edición de bolsillo de Erkenntnis und Interesse, Frankfurt a. M. 1975, pp. 411 ss. 